Faculdade de Engenharia da Universidade do Porto

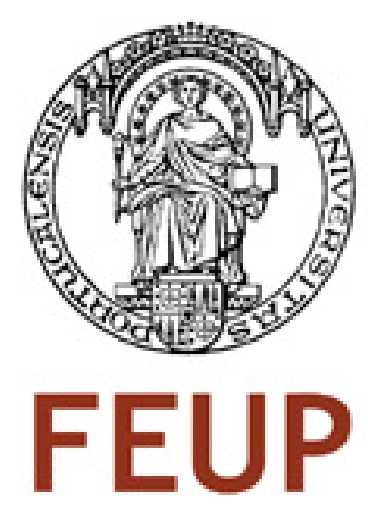

\title{
A Gap Analysis Methodology for the Team Software Process
}

\section{Luís Manuel Gonzalez Amaral}

\author{
FINAL VerSION
}

Dissertation Report

Integrated Master in Informatics and Computing Engineering

Advisor: João Pascoal Faria (Aux. Professor)

June 2009 



\title{
A Gap Analysis Methodology for the Team Software Process
}

\author{
Luís Manuel Gonzalez Amaral
}

Dissertation Report
Integrated Master in Informatics and Computation Engineering

Approved in oral examination by the committee:

Chair: José Faria (Prof. Dr.)

External examiner: Alberto Silva (Prof Dr.)

Internal Examiner: João Pascoal Faria (Prof. Dr.)

July $15^{\text {th }}, 2009$ 



\section{Resumo}

Ao longo dos anos a qualidade do software tem-se tornado cada vez mais importante na engenharia do software. Tal como noutras disciplinas da engenharia onde a qualidade é já um dado adquirido, a engenharia do software está em movimento nessa direcção.

O Team Software Process (TSP) é uma metodologia criada pelo Software Engineering Institute (SEI) cujo principal objectivo é ajudar os engenheiros de software e as equipas a assegurarem a qualidade, a elevada performance, o estabelecimento de objectivos e a gestão dos processos numa organização.

Esta dissertação apresenta uma metodologia para avaliar as diferenças (gaps) entre as práticas correntes da organização e as práticas do TSP de forma a ser possível avaliar os ganhos futuros e as necessidades que a organização vai ter durante e após a implementação do TSP.

A metodologia de gap analysis tem dois pilares fundamentais em termos de recolha de informação: as entrevistas e a análise de documentação. Foram desenvolvidos questionários para guiar a equipa avaliadora na tarefa de condução das entrevistas e ajuda suplementar foi desenvolvida baseada no conhecimento e experiência de trabalho em diversas organizações em qualidade de software. Finalmente um protótipo de relatório também é apresentado neste documento onde um exemplo do seu preenchimento é detalhado.

A metodologia desenvolvida foi aplicada numa conhecida empresa Portuguesa com o apoio e validação do SEI. Foi baseada nos modelos de engenharia de software mais conhecidos CMMI e ISO/EIC 15504 que são hoje standards no processo de qualidade de software. O objectivo desta metodologia é ser rápida e barata quando comparada com os modelos referidos ou com o projecto piloto de avaliação do TSP promovido pelo SEI. Após a primeira utilização da metodologia houve grande satisfação de todas as partes envolvidas. A aplicação da metodologia foi também utilizada na melhoria do processo através das lições aprendidas desta experiência. 


\section{Abstract}

Over the years software quality is becoming more and more important in software engineering. Likewise other engineering disciplines where quality is already a commodity, software engineering is moving into these stages.

The Team software Process (TSP) is a technology created by the Software Engineering Institute (SEI) with the main objective of helping software engineers and teams to ensure quality, high performance, establish goals and improve both personal and process management in the organization.

This dissertation presents a methodology for assessing an organization against the TSP practices so that it is possible to assess the future gains and needs an organization will have during and after the implementation of TSP.

The gap analysis methodology has two pillars in terms of data collection: interviews and documentation analysis. Questionnaires have been developed to guide the team on the task of conduction interviews and further guidance has been developed in what and where to look for information in an organization. A model for the rating has also been developed based on the knowledge and experience of working in several organizations on software quality. Finally a report prototype is also presented in this document where an example of its filling is included.

The methodology developed was applied in one well known Portuguese organization with the support and validation of SEI. It is based on the most know software engineering models CMMI and ISO/EIC 15504 that are nowadays standards for software process quality. The objective of this methodology is to be fast and inexpensive when compared with the models stated or with the SEI TSP assessment pilot. After the first use of the methodology there was great satisfaction of all the parties involved. The application of the methodology has also been used to improve the process with the lessons learnt from this experience. 


\section{Acknowledgements}

A special thanks to...

... my parents for their mentoring and support

... my wife, Marta, for her patience and dedication

... my advisor and co-worker, João Pascoal Faria, for his guidance and teaching

... and my co-workers at FEUP CIQS, Pedro Castro Henriques, Pedro Gomes and Raul Vidal for the great sharing of experiences. 


\section{Index}

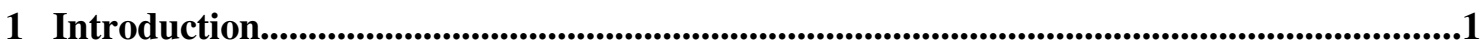

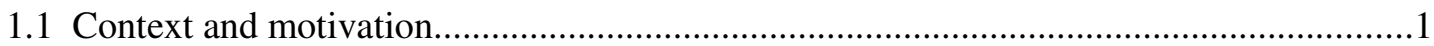

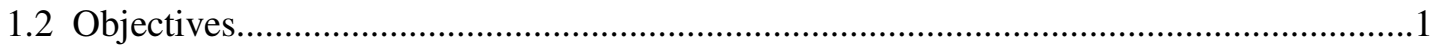

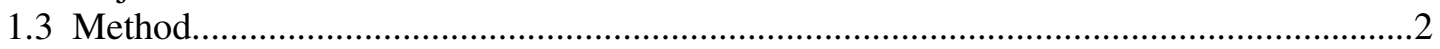

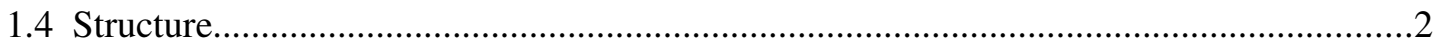

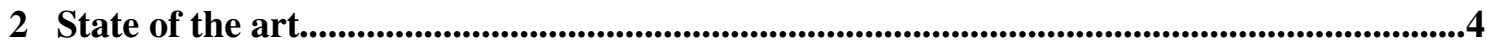

2.1 What is the TSP

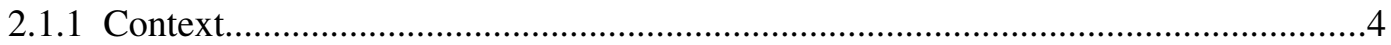

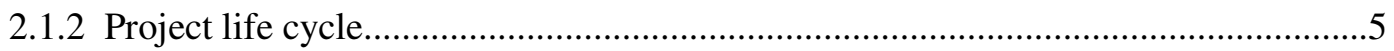

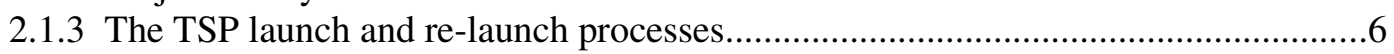

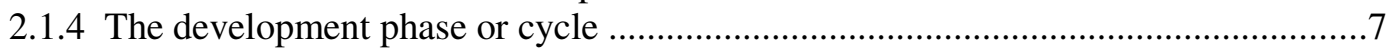

2.1.5 The phase, cycle or project post mortem................................................................

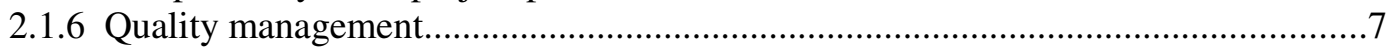

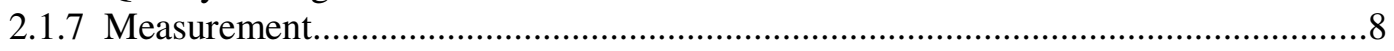

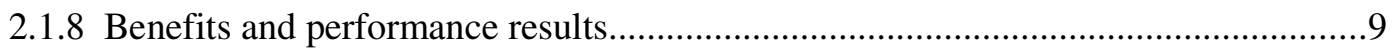

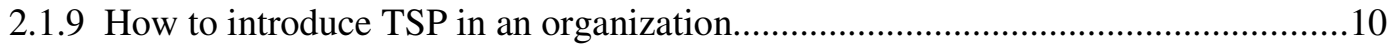

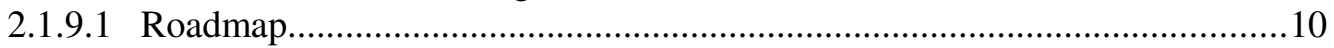

2.1.9.2 Criteria for choosing people and projects.................................................10

2.1.9.3 Synergies with other process improvement initiatives..................................11

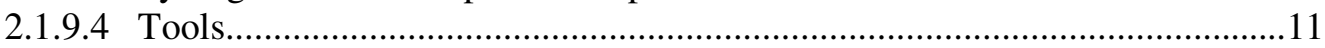

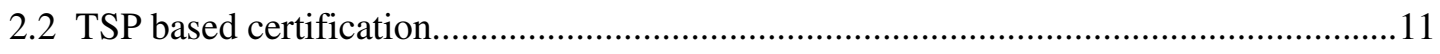

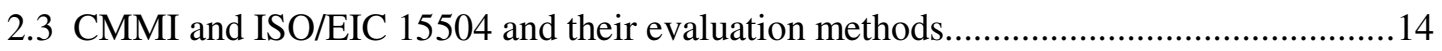

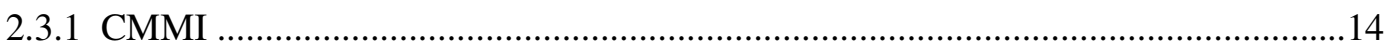

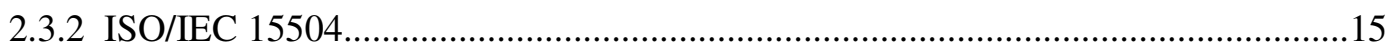

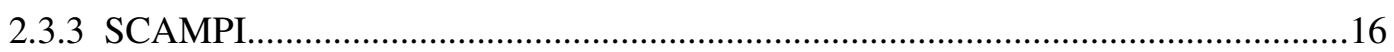

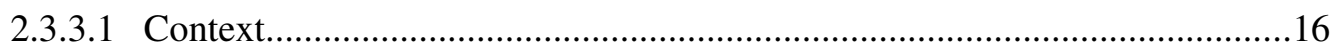

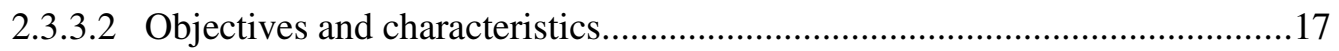

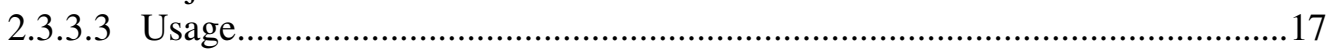

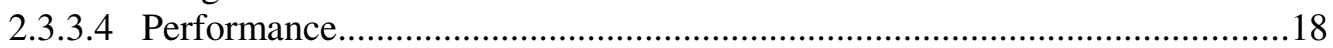

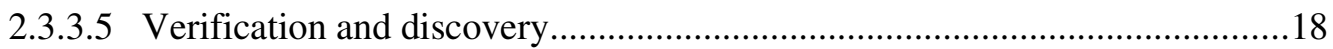

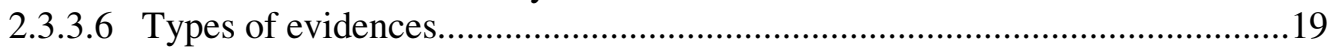

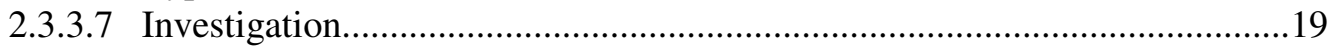

2.3.3.8 Practice Implementation Indicators (PII) ..................................................20

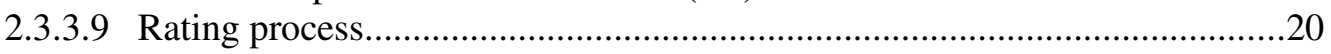

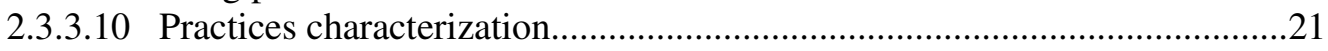

2.3.3.11 Effective team practices...........................................................22

2.3.4 ISO/EIC 15504 assessment method......................................................23

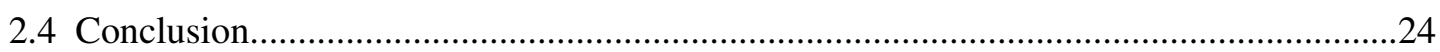

3 TSP gap analysis methodology.............................................................................................26

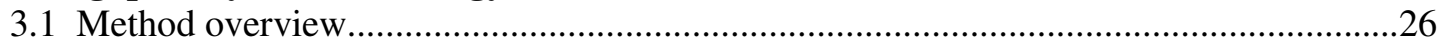




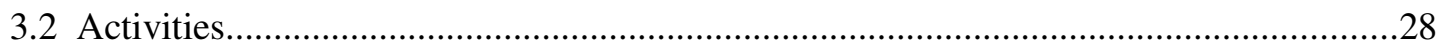

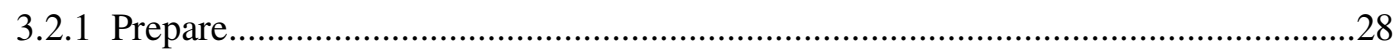

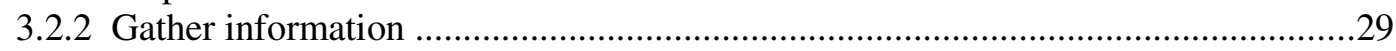

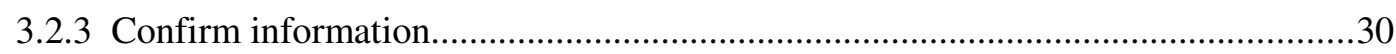

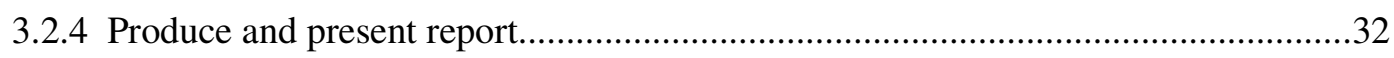

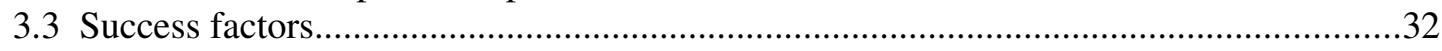

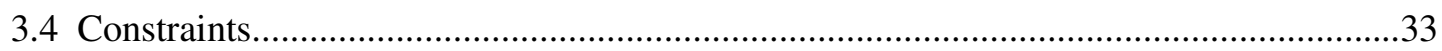

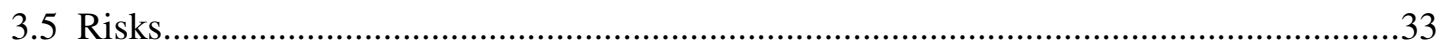

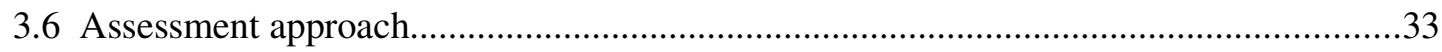

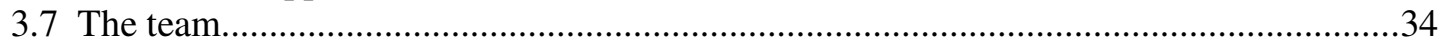

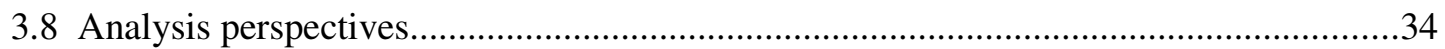

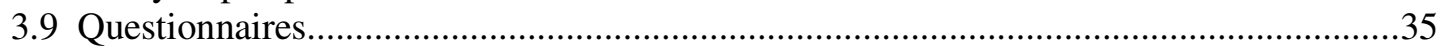

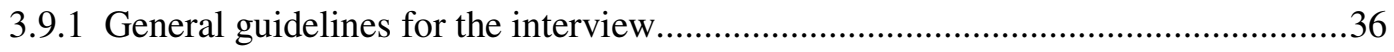

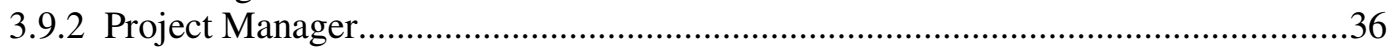

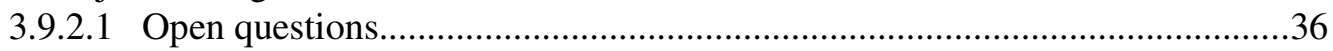

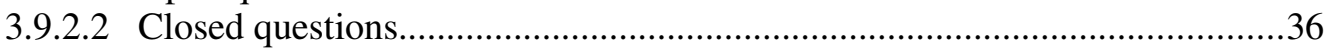

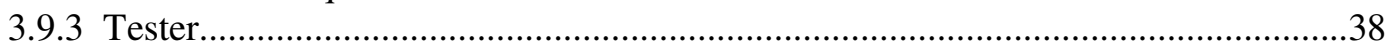

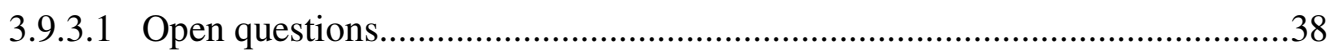

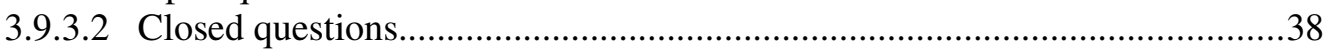

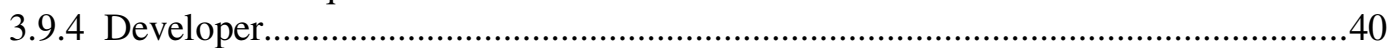

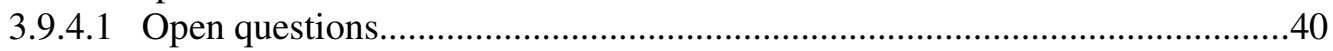

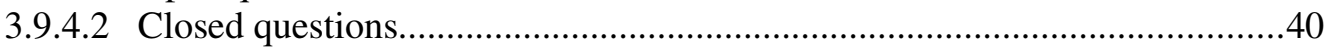

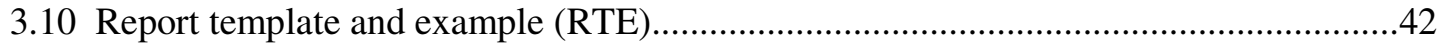

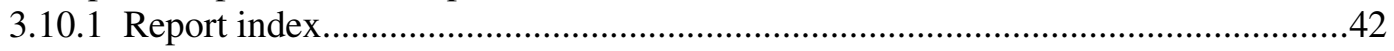

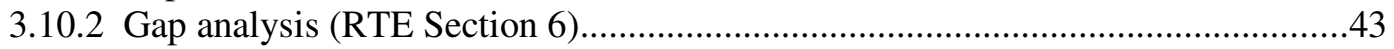

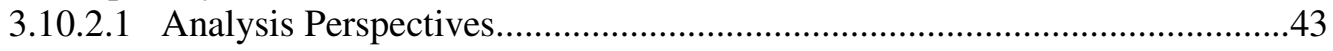

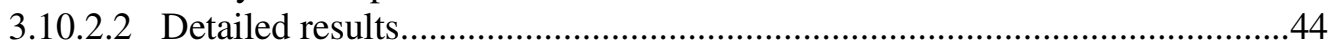

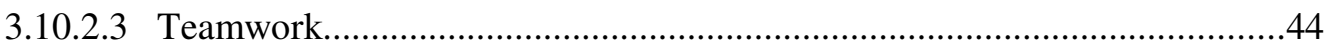

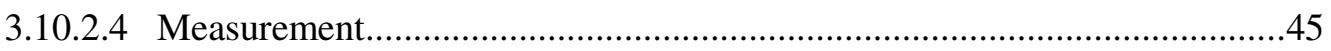

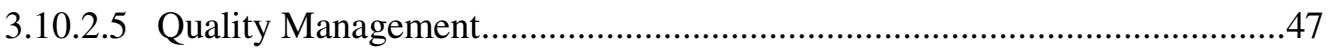

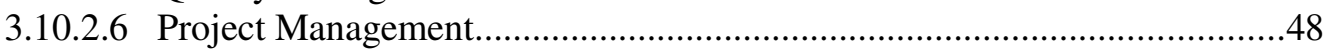

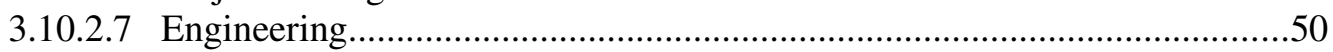

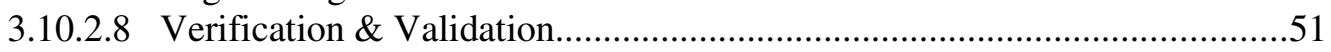

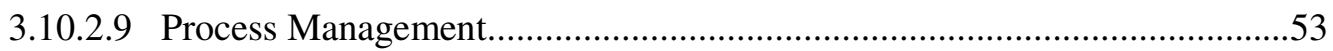

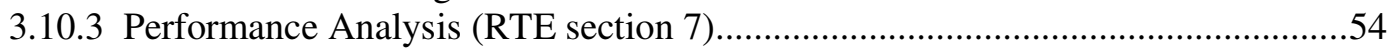

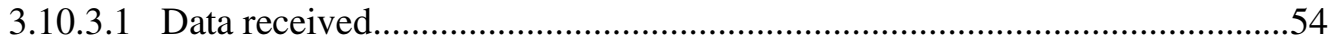

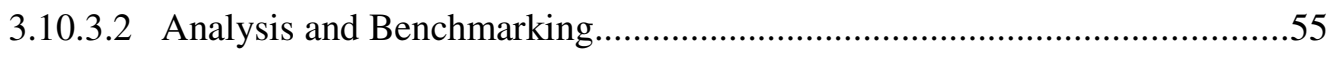

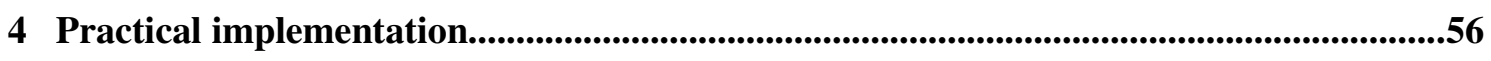

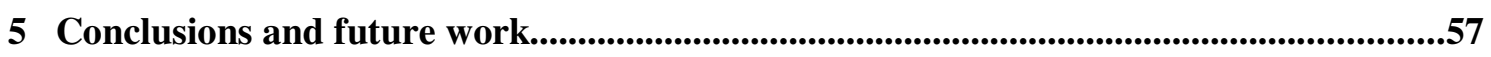

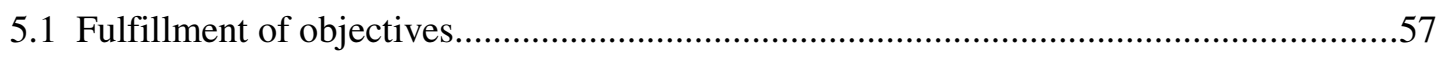

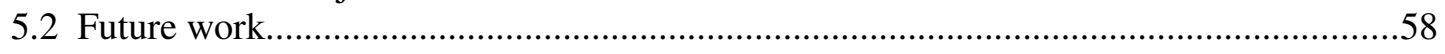

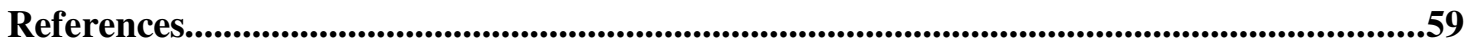




\section{List of Figures}

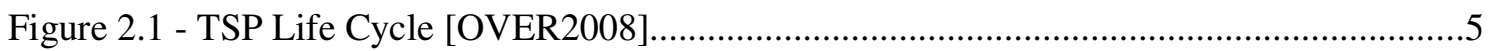

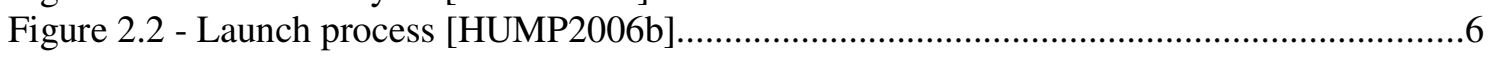

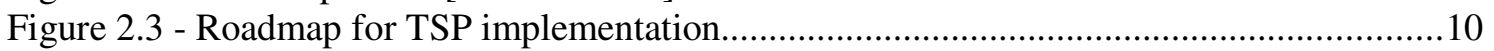

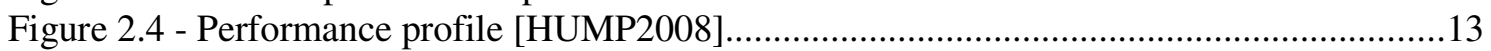

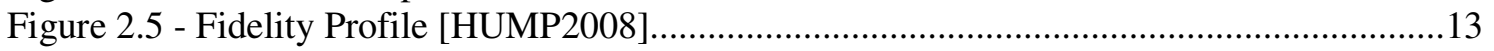

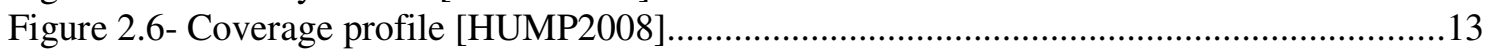

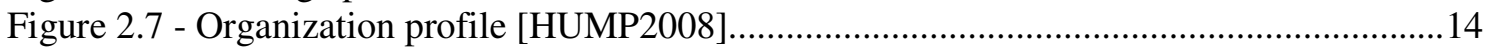

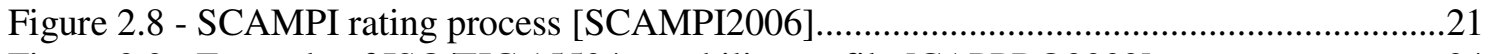

Figure 2.9 - Example of ISO/EIC 15504 capability profile [CAPPRO2009].................................24

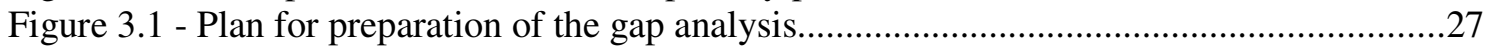

Figure 3.2- Effort Evaluation - The lower values in the graph show higher gaps.......................44

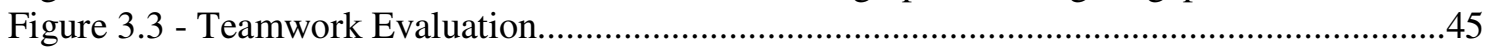

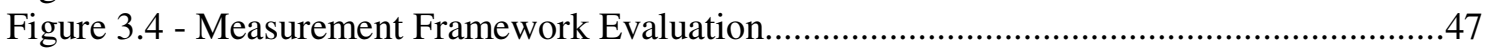

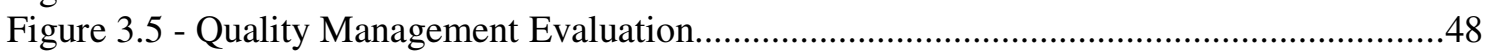

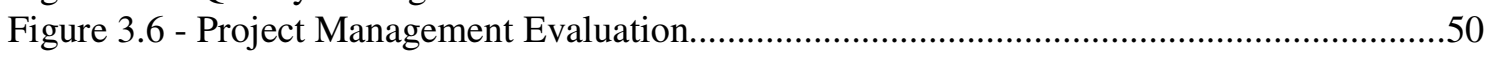

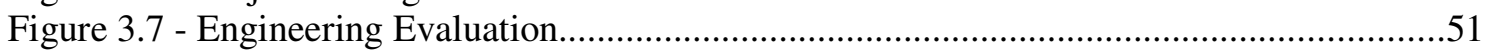

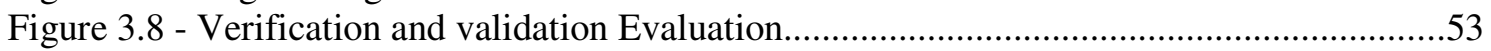

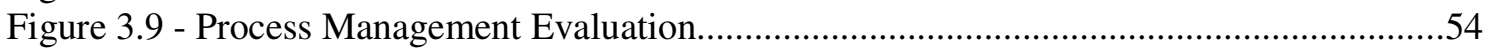




\section{List of tables}

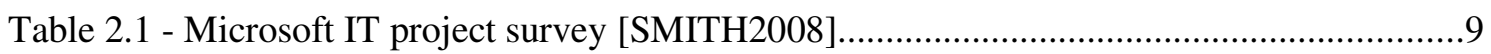

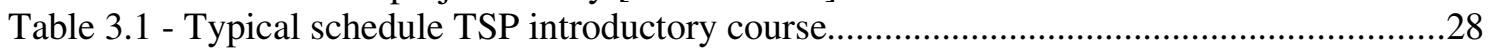

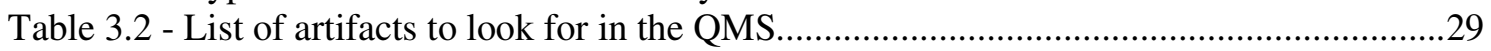

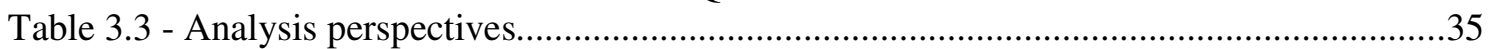

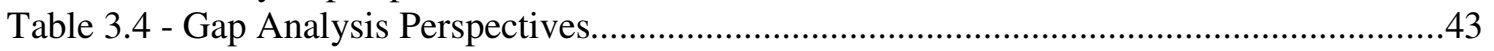

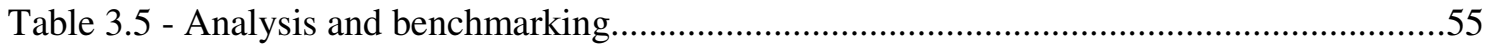




\section{Abbreviations and Symbols}

\begin{tabular}{|l|l|}
\hline ARC & The Appraisal Requirements for CMMI v1.2 \\
\hline CMM & Capability Maturity Model \\
\hline CMMI & Capability Maturity Model Integration \\
\hline EIC & International Electrotechnical Commission \\
\hline ESA & European Software Agency \\
\hline FTE & Full-time equivalent \\
\hline ISO & International Organization for Standardization \\
\hline IT & Information Technology \\
\hline KLOC & One thousand lines of code used to measure the size of a software program \\
\hline KSLOC & One thousand source lines of code used to measure the size of a software program \\
\hline ODC & Orthogonal Defect Classification \\
\hline PII & Practice Implementation Indicators \\
\hline PIP & Process improvement Proposal \\
\hline PROBE & Proxy Based Estimation \\
\hline PSP & Personal Software Process \\
\hline QMS & Quality Management System \\
\hline SCAMPI & Standard CMMI Appraisal Method for Process Improvement \\
\hline SDP & Software Development Process \\
\hline SEI & Software Engineering Institute \\
\hline SPICE & Software Process Improvement and Capability Determination \\
\hline TSP & Team Software Process \\
\hline
\end{tabular}




\section{Introduction}

\subsection{Context and motivation}

In the context of software engineering, software quality is the degree to which a system, component, or process meets specified requirements as well as customer or user needs or expectations [IEEE1990]. Nowadays software quality is becoming increasingly more important as software engineering is becoming more and more an exact science where errors are less and less tolerated. Software engineering is moving towards the direction of other engineering disciplines, likewise civil engineering where bridges are standing and in use for more than 2000 years. The Team Software Process (TSP) methodology was developed based on these premises.

After the release of TSP, it has been implemented in a wide range of organizations world wide. Over recent years its growth has increased specially in the USA, Mexico and Asia among other countries.

It is a fact that TSP contributes greatly to the improvement of team and personal performance as well as the quality of the products developed. These facts make TSP contributing to a high cost reduction in the organizations making them more efficient and effective. TSP has also been used very broadly by organizations that want to reach the higher levels of CMMI (levels 4 and 5). CMMI is today the most known and used benchmark model regarding software process quality.

Due to these facts, it is becoming more and more important for organizations to know how far they are from TSP practices not only because of the cost of implementing TSP, but also to evaluate the gains that they can have when applying this methodology when compared with their current practices.

\subsection{Objectives}

The project described in this dissertation has the main objective of defining a methodology to help in the evaluation of the current practices of an organization that is considering implementing TSP by means of a gap analysis. 


\section{Introduction}

Being TSP a technology that brings big gains in terms of quality, productivity and predictability in projects, leading to cost savings, it is important to create an easy to use methodology to evaluate the distance of an organization practices to TSP.

The methodology should be easy to use and understand by someone that is familiar with software engineering and it should be a methodology that is quick to follow and produce results. The results should be fast to read and there must be material produced that is easy to read by senior management of organizations.

It is one of the objectives that this methodology can be applied both from the inside of the organization, meaning that an internal assessment team can follow the steps provided or from the outside of the organization, where an external entity is hired to perform the assessment and provide the results.

It is also objective of this work to show results of a case study of the methodology.

\subsection{Method}

The method for producing this work started with the analysis of the TSP methodology together with the state-of-the art methodologies for process assessment in software engineering: The Standard CMMI Appraisal Method for Process Improvement (SCAMPI) and the ISO/EIC 15504 assessment framework. Part of this study includes the investigation of articles about these 3 main topics.

After this initial research the methodology of assessment started to be built. It was decided to produce as part of this methodology, not only a planning and executing framework but also questionnaires to help the assessment team to perform their job and a skeleton of the final report to be delivered to the organization's management.

The following steps after the method was developed and reviewed were the real life test in an organization. A company that was interested in TSP has been approached in order to test the methodology and the needed steps described in it have been followed and improved based on the experience of this implementation.

After this the final adjustments have been done as well as this dissertation has been written and reviewed.

\subsection{Structure}

The current dissertation is organized in 5 chapters. In the first one an introduction to this work is done including the objectives of this dissertation.

In the second chapter the themes of TSP, SCAMPI and ISO/EIC 15504 are presented, including its advantages and best practices. This chapter details the methodology for implementing TSP as well as its success factors. Regarding the assessment methods CMMI and ISO/EIC 15504, the way they should be performed is described as well.

In chapter three the methodology of assessing organizations according to TSP is described. In this chapter, besides the method used to do this assessment, it is also included a proposed plan for the assessment, questionnaires to help the assessment team and examples of parts of the final assessment report. 


\section{Introduction}

In the next chapter, the forth one, a short description of the practical application of this methodology is described. No further information about this methodology evaluation can be shown due to confidentiality reasons.

In the fifth chapter the conclusions of this work are described. There are also references to the future work beyond this dissertation. 


\section{State of the art}

In this section it is described the TSP methodology that is a key point of this dissertation. This chapter also describes the two most common methodologies used to assess the software development processes in an organization. They are based on the most know models for process improvement in software organizations: CMMI and ISO/EIC 15504.

\subsection{What is the TSP}

\subsubsection{Context}

The success of organizations that produce software-intensive systems depends on well managed software development processes. Implementing disciplined software methods is often a challenge. Organizations seem to know what they want their teams to be doing, but they have difficulties on how to do it. The Team Software Process (TSP), together with the Personal Software Process (PSP), were designed to provide both a strategy and a set of operational procedures for using disciplined software process methods at both the individual and the team levels. Organizations that have implemented the TSP and PSP have experienced significant improvements in the quality of their software systems and have reduced schedule deviation. Countries like Mexico for example are betting to become more efficient in software development by introducing a national TSP initiative [GARCIA2008].

The TSP is designed to guide the development team while they design and develop software-intensive systems. It will work for many other kinds of teams, however its focus is on software development work being that the industry where it has been most widely used. The TSP process guides development teams and their management in planning and developing quality products on predictable schedules. It provides detailed guidance and its process scripts lead the developers through launching and operating their teams. During the initial launch process the development team learns the product requirements and project goals from management. The team produces a plan to meet the objectives. At the end of the generally fourday launch, the team meets with management to discuss and agree on the team's plan and delivery commitments [HUMP2006a].

After the launch, the TSP process guides the team and the team leader in working as a selfdirected team. A self-directed team defines its own strategy and processes, produces its own 
plan, and negotiates its own commitments with its management. When the team members are properly trained, they typically deliver quality products on schedule. They also find their work much more productive and much more rewarding [HUMP2002].

The individual skills that engineers need to wok in a TSP team are previously developed in one or two weeks of PSP training. The PSP is a self-improvement process designed to help each engineer control, manage and improve his way of work. It is a structured framework of forms, guidelines and procedures for developing software. Properly used, the PSP provides the historical data needed to better make and meet commitments and it makes the routine elements of the job more predictable and more efficient [HUMP1997].

As each person becomes more familiar with PSP, he will learn how to define, measure and analyze the processes. With increased experience each person will be able to enhance his processes to take advantage of new technologies, tools and methods. Above all, it enables each person to understand his own performance and to see where and how to improve it.

The PSP purpose is to help the software engineer to be better. It is a powerful tool that can be used in many ways, for example to manage work, assets and talents and to build skills. It can help to improve the planning, the performance tracking and the measurements of the quality of the products.

\subsubsection{Project life cycle}

Figure 2.1 details the TSP project life cycle where an iterative approach is followed. Over the next sections a detailed description of each phase is provided in order to give full understanding of the project life cycle TSP implements.

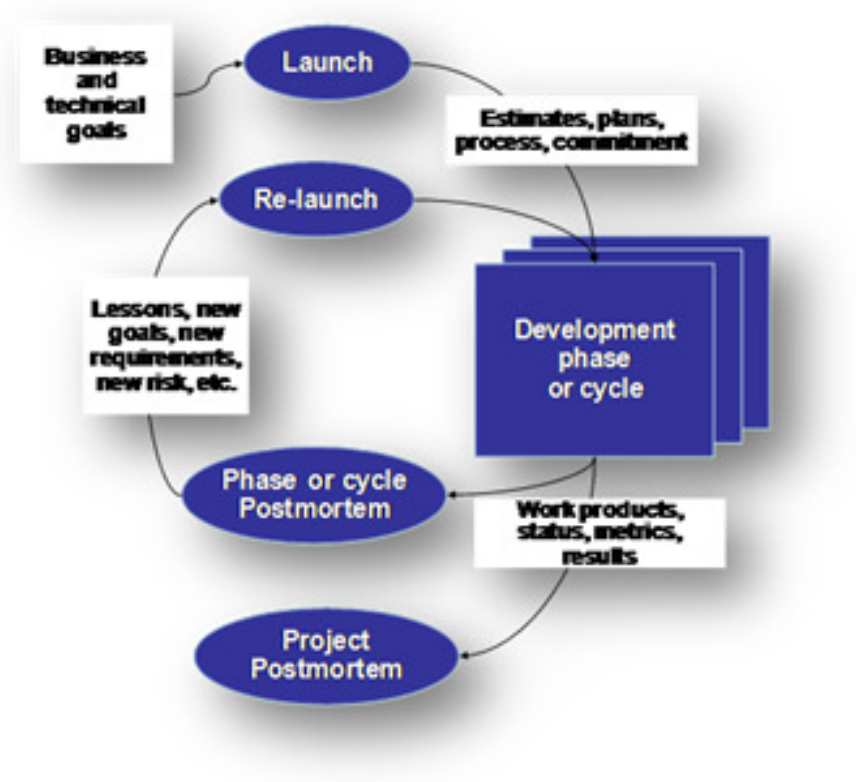

Figure 2.1 - TSP Life Cycle [OVER2008] 


\subsubsection{The TSP launch and re-launch processes}

The TSP cycle starts with a 4-day launch that follows the process shown in figure 2.2:

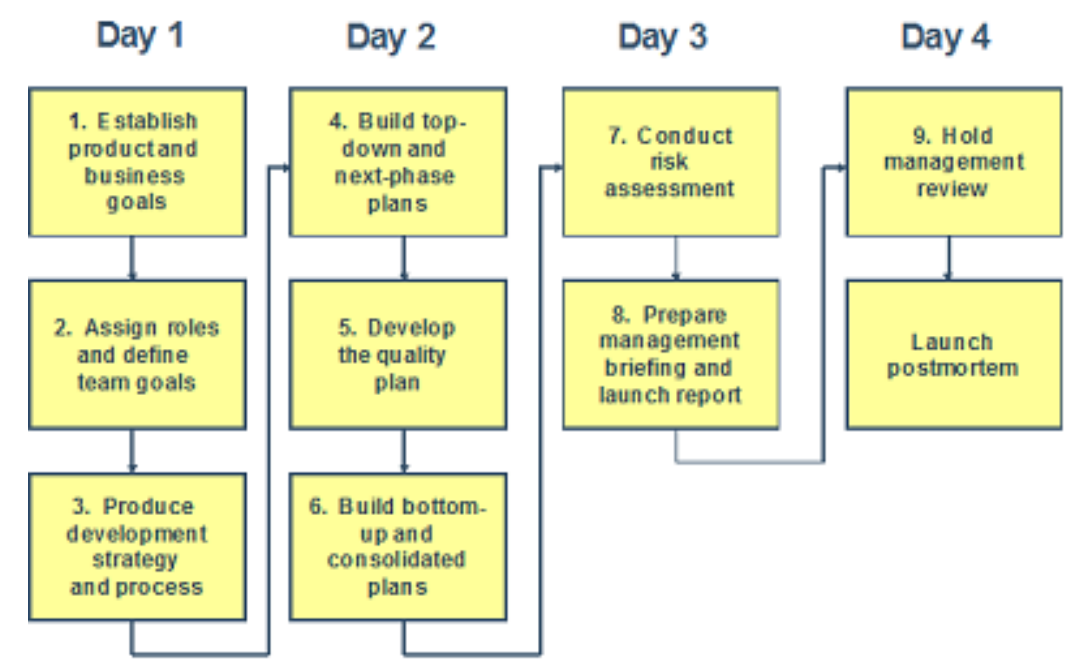

Figure 2.2 - Launch process [HUMP2006b]

There are many reasons to start projects with a launch. The process of forming and building a team does not happen by accident and it takes some time. Teams need to establish their working relationships, determine members' roles and agree on their goals. An hour or so spent on team building issues at the beginning of the project saves time later.

Defining the roles and agreeing on who will handle each role is an essential first step in formation. The team leader together with the team make the initial assignment of the roles based on the preferences of each of the elements. These roles can change as time goes by according to preferences and adaptation of the team to the project and team members.

During the launch period the team will get together and do the planning in detail for the next cycle using all the TSP concepts and techniques. These go from team building to detailed planning always using as much as quantitative data as possible. After the completion of the launch or re-launch there are a set of documents that are produced and that will support the management and execution of the cycle.

Prior to these launch activities there are launch preparation tasks that usually range from 6 to 8 weeks before the start of the project (in case of a re-launch this period is highly shortened and the project does not stop due to this fact). These tasks include all the preparations for the launch including team readiness, team training, scheduling among other relevant tasks.

The concept of self-directed teams is introduced and institutionalized. Besides having a high degree of commitment to the plan these teams sense what is needed to be done without being told and they search for help to do whatever is needed to get the job correctly done. Members have both execution and management roles giving them ownership of the process and the plan. They grow a dedication to excellence.

The launch and execution of a TSP project requires a coach. The coach can help the team to follow the process making sure that any deviations are fixed as soon as possible. The coach also brings an independent view to solve the problems as well is better accepted to the team members once he is not part of the team. 
The relaunch is a copy of the launch process with the difference that by the time a relaunch is done one or more launches haver already been made by team, making the process more possibly shorter and more fruitful.

\subsubsection{The development phase or cycle}

A TSP development iteration can have multiple phases. Either it will contain one only phase of the development life cycle (e.g. high level design) or it will contain several phases that will form a cycle. One TSP cycle can contain a full software development life cycle. The TSP does not enforce any specific technology regarding the way any development should be done once it can be applied to different phases of software engineering (design, development, etc.).

However TSP always enforces discipline, measurements, reviews and inspections. These areas are key to success of a TSP implementation. During the development phase or cycle the documents produced during the launch together with the TSP tools available for managing the process will be the main management tools. They will allow the team to track its progress, assess risks, assess goal completion, follow the earned value plan, among other important tasks. The use of these tools and documents will also produce reports to higher management and customer at specified intervals.

During this phase coaching is crucial to making sure the team follows the TSP process and works towards meeting the planned goals. Improvements in performance depend much on the team coach. Without a good team coach the teams will not reach their best performance.

\subsubsection{The phase, cycle or project post mortem}

Every TSP development iteration ends with a postmortem, which provides a structured way to learn and improve. In the postmortem what has been done is examined and compared with what was planned to be done. The team looks for improvement opportunities and decides how to change their practices for the next cycle, phase or the next project. Merely trying harder will not produce consistent improvement. The teams must actually change what they do. They can either change the process or discover how to better follow the process that exists.

By using the postmortem process there will be changes from one iteration to the next. The first TSP iteration provides a baseline. The team assess the products produced, the effort spent to produce them and the process steps followed. The accuracy of the plans is determined as well as the suitability of the processes. Problems are identified, their causes determined, and prevention measures devised. The postmortem is the appropriate point to identify specific improvement opportunities and decide where and how to incorporate these changes into the personal and team processes.

\subsubsection{Quality management}

A quality product satisfies the customer. To satisfy customers, products must provide the functions and performance the users need, be delivered on time and must work reliably enough to do the customer's job.

The principles of software quality management are not new and they come directly from general quality improvement principles (most of them applied in the automotive industry since many years). The basic principles of quality management have been used successfully in many other fields. These principles are as follows: 
State of the art

1. In any quality program the principal objective is to satisfy the customer

2. Management must make quality the top priority, not a top priority

3. The people doing the work must own the quality program

4. To improve quality the process must be changed

5. Quality must be measured

6. Doing the job right always costs less in the long run

People tend to think of quality as the final result or destination. It is not. It is a journey that never ends. As you measure and manage quality you will learn more about it. Then each improvement will provide the knowledge, experience and data needed for the next steps. Organizations should focus on continuous improvement and help the teams to truly believe and follow principles of quality management.

First of all there should be a focus on the personal responsibility to ensure that what is delivered is well done. This responsibility and its results can be boosted by doing personal reviews that after this can be improved by running team inspections. Team inspections together with personal reviews are two of the most effective methodologies to find and correct issues. Quantitative management is the next step in making sure that the delivered artifacts have good quality and that they improve from delivery to delivery.

\subsubsection{Measurement}

Measurement is fundamental to the TSP process. To measure the work and the work products, the team resources must all use the same defined process, know how to measure that process and work products and consistently measure them. If they do not act this way, their measurements will be inaccurate, inconsistent and largely useless.

It is necessary to measure to get data and this data will help the organization on the following:

- Gain quantitative understanding of their performance

- Evaluate a product, process or organization

- Control a product or a process

- Make an estimate or plan

TSP focuses on four base measures:

- Size

- Time

- Defects

- Schedule

Some of the high level measures are divided in lower level ones in order to clear the scope and need of each of them. As an example the size can be divided in baseline code, deleted code, modified code, new code and reused code.

With these four base measures it is possible to extrapolate a large number of other measures that will be helpful in guiding future projects and evaluating the current one. There are quite a big number of important measures that can be extrapolated from these measures such as 
estimation accuracy (size/time), prediction intervals (size/time), time in phase distribution, defect injection phase distribution or defect removal phase distribution.

\subsubsection{Benefits and performance results}

The success of organizations that produce software intensive systems depends on wellmanaged software development processes. Software nowadays is critical to most of the businesses and if it is not well managed the organization using the software might incur into issues in other areas related with this specific topic: software. TSP can help organizations in managing and improving the quality of the software needed in the organizations.

TSP was developed to improve the performance of organizations having always in mind the four base measures that any organization should focus when developing software: size, time, effort and defects. The TSP processes will bring knowledge organizations and their resources on how to manage these measures, how to to estimate using them and how to improve their performance. The ultimate goals in mind are to better serve the customer, better treat the employees and increase profitability.

The SEI has done several studies on the advantages of TSP [DAVIS2003]. The numbers show excellent performance results. Looking at the defect density statistics, in a study of 20 projects in 13 organizations, TSP teams had an average defect density in released code of 0,06 defects per added and modified KSLOC. This is more than one order of magnitude better than the average CMMI level 5 organizations. In the same study, cost and schedule have been inquired and measured. Organizations adopting TSP report that project team actual cost and schedule are typically within 5\% to $10 \%$ variance without sacrificing features. Another study has shown one organization delivering 250KSLOC on time and budget and had only 3 weeks of acceptance testing and 4 post-release defects.

Some known organizations published case studies of using TSP on their software development departments. Microsoft IT invested \$3M over six years and accounted to have saved $\$ 84 \mathrm{M}$ on 200 software projects (Table 2.1). Intuit, a company which flagship products manage small businesses and personal finances routinely achieves $30 \%$ more functionality in each release after introducing TSP. ABB, one of the world's leading engineering companies, reduced system test to $4.2 \%$ of software development life cycle.

\begin{tabular}{|l|c|c|}
\cline { 2 - 3 } \multicolumn{1}{c|}{} & $\begin{array}{c}\text { Non-TSP } \\
\text { Projects }\end{array}$ & $\begin{array}{c}\text { TSP } \\
\text { Projects }\end{array}$ \\
\hline Released On Time & $42 \%$ & $66 \%$ \\
\hline Average Days Late & 25 & 6 \\
\hline Mean Schedule Error & $10 \%$ & $1 \%$ \\
\hline Production Defects/KLOC & 1.8 & 0.5 \\
\hline Sample Size & 80 & 15 \\
\hline
\end{tabular}

Table 2.1 - Microsoft IT project survey [SMITH2008]

All in all TSP can bring enormous results to organizations that have a focus on software development by improving their processes and institutionalize measurements among the people, the teams and the whole organization always improving the quality and performance of the deliverables, the customer satisfaction and saving money. 


\subsubsection{How to introduce TSP in an organization}

In this section it is presented a typical roadmap for implementation of TSP, including the criteria for project choice, strong synergies that result from the application of TSP to achieve high maturity levels, as well as the expected development on tools.

\subsubsection{Roadmap}

The first step for the beginning of the project is the approval by the organization and signing the joint contract between the parties which already will include the dates and selection of the two projects for launch.

After signing day, the setup takes between 1 and 2 months. After that period, the following main activities will take place:

- Meeting for detailed planning [1 day]

- Executive Seminar [1 day]

- PSP Training [5 days]

- TSP training [5 days]

- Projects begin [3-6 months]

- Launch

$\circ$ Coaching

- Post Morten

- Executive review [1 day]
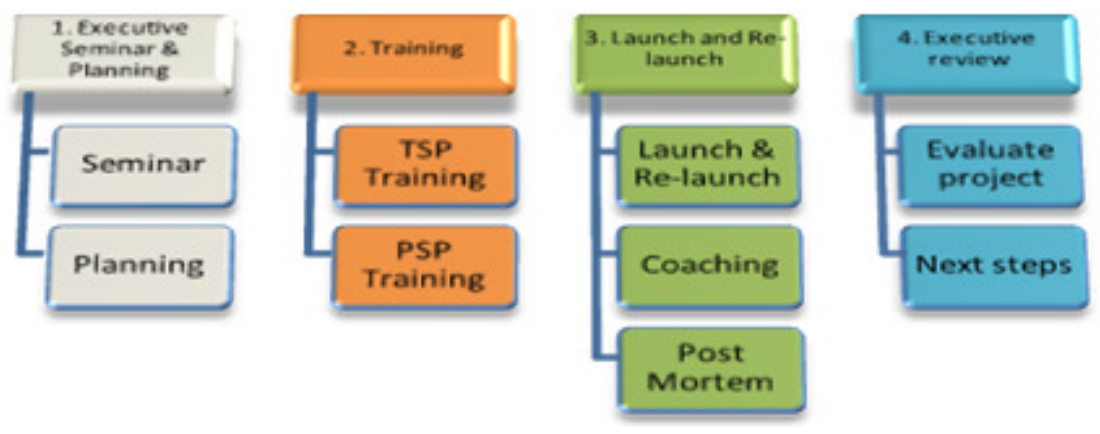

Figure 2.3 - Roadmap for TSP implementation

This roadmap details the process of launching a pilot with 1 or 2 projects. After the successful pilot projects it is high time for the rollout throughout the organization which involves training internal change agents (instructors and coaches) that lead the spreading of the TSP practices to the rest of the organization on a project by project basis.

\subsubsection{Criteria for choosing people and projects}

The projects and teams to be chosen for TSP should follow the considerations bellow:

- Projects that involve champions and volunteers - it is very important to have energetic, competent and motivated organization champions to catalyze the results and amplify and multiply them in the organization, spreading the word and good practices. 
Volunteers in these situations are usually seen as the early adopters and being volunteers usually gives the organization a higher level of confidence on their will to adopt the new processes.

- Projects of 3 to 6 months duration - The 3 to 6 months duration is ideal to see the results in short term in a consistent way and to guarantee that there is time enough to see the improvements.

- Projects that do not have very unknown technologies - It is recommended to have projects where the technologies are known so that the advantages of TSP can be shown faster as they will not be dependent on the technology.

- Projects with stable scope - Chaotic projects could increase the risk of the loss of focus on the learning aspects by organization teams and could lead to not applying some of the needed practices for TSP being successful.

- Projects that are starting - The projects starting bring a cleaner environment for project and new best practices instantiation. Maintenance projects are not recommended for pilot projects (although TSP can also be applied to this kind of projects).

\subsubsection{Synergies with other process improvement initiatives}

The six sigma initiative will provide a framework of tools and training in the organization in order to quantitatively analyze the information. This project will be an excellent complement to the TSP project that will have a more bottom-up approach.

It was verified that the base measures utilized by the six sigma project are the same as the TSP project. TSP offers a more complete set of derived measures and tools for the quality and engineering measures.

Several organizations have included in the context of a CMMI implementation with the objective of accelerating the achievement of a maturity level. NAVAIR, with the combined implementation of CMMI and TSP managed to reach the level 4 of CMMI in a record time with a return on investment of several million US dollars [ARMAND2006].

\subsubsection{Tools}

TSP comes with a set of tools which are recommended for the pilot projects.

The analysis of the TSP tools and the organization tools will allow the identification of functionalities needed to be incorporated in the organization own legacy tools making sure tools will not be problems but always solutions for further TSP growth.

\subsection{TSP based certification}

The SEI started to develop a method for certifying software organizations according to the TSP methodology. This methodology has been developed together with the Mexican government initiative based on the national objective of being the world's highest quality software supplier by 2013 [HUMP2008].

This method can be performed in 3 ways having each of them its strengths and weaknesses:

- Certification of individuals

- Certification of processes 
- Certification of products

When one is certifying an individual the main criteria are the skills, the experience and the knowledge. This can be done through verifying references and experience and has the advantages of having a clearly defined scope and criteria and being easy and cost-effective to administer.

Moving to the process certification, the way of doing this would be to certify according to a defined capability criteria likewise CMMI. This can be done through an organization assessment (as the method described in the next chapter). It also has the advantage of having a clearly defined scope and criteria as well as enabling flexibility on implementation and on the technologies used. The main disadvantages are the difficulties in assuring that the process will be used properly, and that the process will produce the desired results. It also makes the process of assessment more expensive as it has to be quite comprehensive.

When looking at certifying products some criteria has to be met in order to proceed with the method: function, performance and quality. The great advantage of this method is that it addresses specific needs, however it is only available after the product is ready or almost ready and has to rely on testing making it most of the times expensive and time consuming.

This method will surely be very accurate, objective and repeatable in organizations using TSP, as TSP data is very good and broad for this purpose. With the data different certification profiles can be produced.

The TSP organization certification strategy uses a combination of the 3 different strategies, making it very complete, but also expensive. The certification of team members ensures that they know the proper methods and how to gather and use data. The process validation ensures that an effective and defined process is faithfully followed. The product quality verification checks the quality of the products as well as the customer satisfaction.

The certification profile is a visual display of numeric scores. It provides a comprehensive picture of organizational performance being a product of the certification process and a scorecard that characterizes the organization capability. It has 3 components:

- Performance

- Fidelity

- Coverage

The performance profile shows the actual product and project performance. The Figure 2.4 shows this profile.

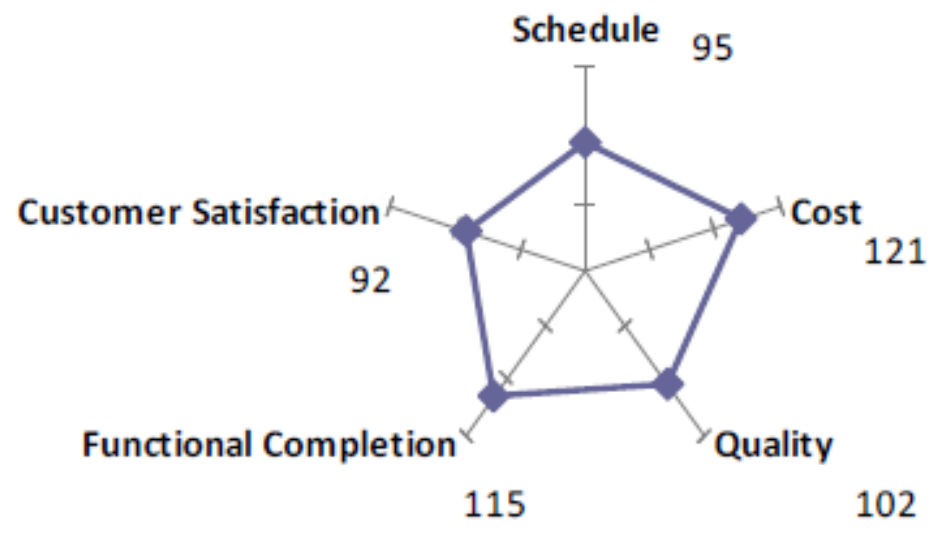


State of the art

Figure 2.4 - Performance profile [HUMP2008]

The fidelity profile shows the project's ability to obtain consistent results. An example of this profile can be seen in figure 2.5 .

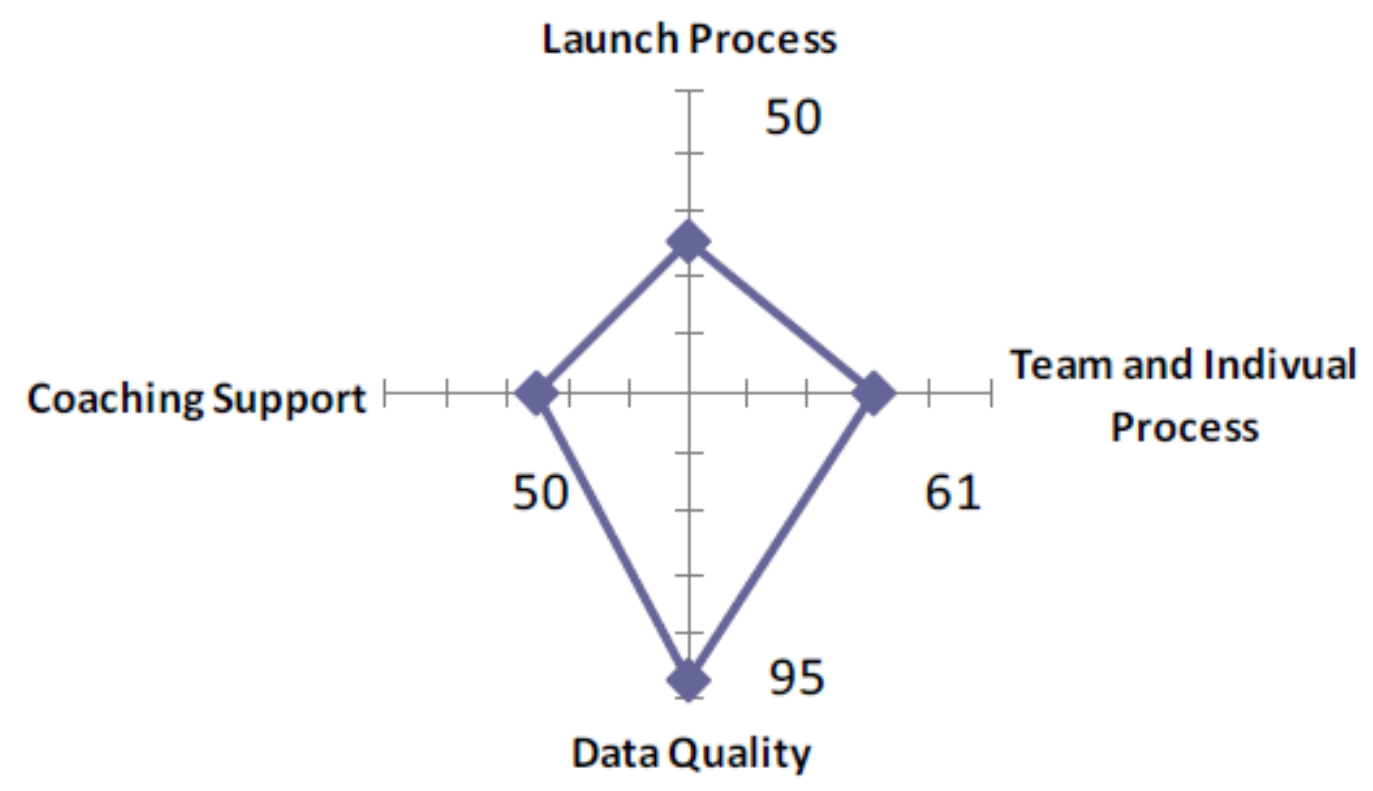

Figure 2.5 - Fidelity Profile [HUMP2008]

The coverage profile objective is to measure the institutionalization of TSP. Figure 2.6 shows an example of this profile.

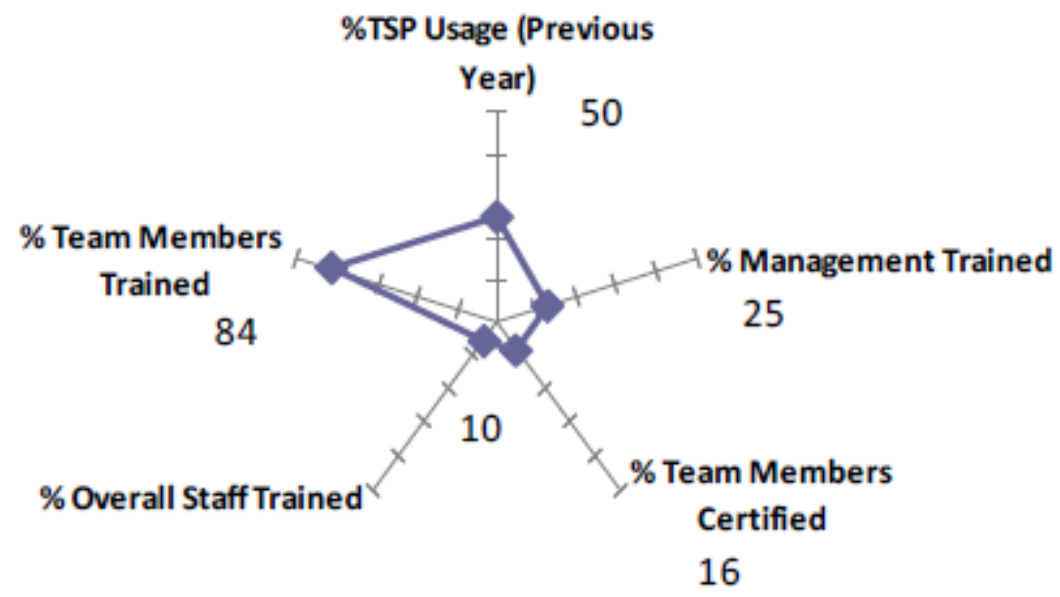

Figure 2.6- Coverage profile [HUMP2008]

All these profiles can now be combined in a graph that gives a 3D perspective of the company. Figure 2.7 shows this view. 


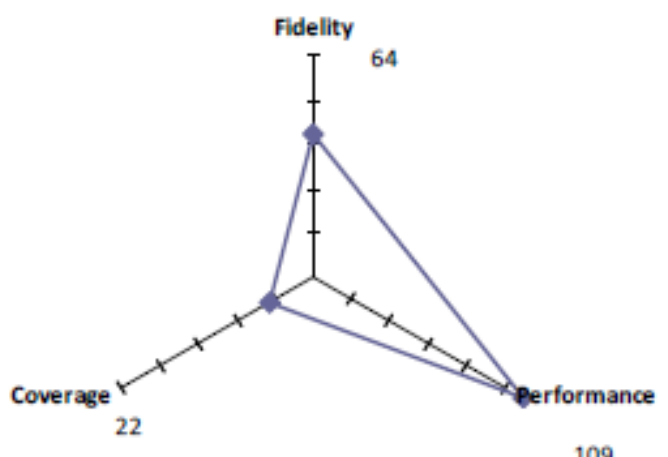

109

Figure 2.7 - Organization profile [HUMP2008]

The process for building this profile and going through the assessment requires a request from the organization to perform the TSP Organization Certification. After this request the organization has to collect data and meanwhile a qualified assessor is selected in order to review the data and process it according to the assessment rules.

In terms of the needed data, most of it is already available in the SEI TSP tools (or any similar tools used by the organization to implement TSP) making its gathering a fairly easy and quick job.

Like any other certification, this one also brings differentiation of the organization towards the market as well as demonstrates commitment of the management towards quality. It also brings benefits to the organization's customers by assuring the performance of the organization among other benefits. This certification promises to help to identify superior software organizations and motivate continuous improvement specially thanks to the defined profiles.

This TSP certification has only been piloted in one organization and there is still no tool and infrastructure available for the market. The current SEI plan is to continue piloting it and improving it in other organizations prior to releasing it to the market. This method is currently being piloted in Mexico.

Although the goal of this work is to develop a gap analysis methodology for organizations that are not using (but instead considering using) TSP, some of the elements of this approach can be adapted.

\subsection{CMMI and ISO/EIC 15504 and their evaluation methods}

\subsubsection{CMMI}

Capability Maturity Model Integration is a process improvement maturity model for the development of products and services. It consists of best practices that address development and maintenance activities that cover the product lifecycle from conception through delivery and maintenance [CRISIS2007].

The purpose of CMMI is to help organizations to improve the way they develop, maintain, buy and service software. The model has 3 constellations, development acquisitions and services. The one that is reference in this dissertation as CMMI is the development one. 
The CMMI Project was initiated based on a 1997 review of SEI activities by the Office of the Under Secretary of Defense and interest expressed to the SEI by the CMM user community. The CMMI project was formed to improve the usability of CMM technology for a set of disciplines including and extending beyond software engineering. As the CMMI concept developed, the scope of the project was restricted to a few disciplines most needed by government and industry until the concept was proven.

The selection of software engineering, systems engineering, and integrated product development CMMs was made by industry and government participants for the initial proof-ofconcept phase. However, the product suite was designed to accommodate expansion of its discipline coverage and product and project lifecycle coverage. The following models were used as sources in the development of the first set of CMMI models [SEI2009b]:

- SW-CMM Version 2 Draft C

- EIA/IS 731 (SECM)

- $\quad$ IPD-CMM Version 0.98

CMMI is being adopted worldwide, including North America, Europe, Asia, Australia, South America, and Africa. This kind of response has substantiated the SEI's commitment to the CMMI models.

The CMMI Product Suite is at the forefront of process improvement because it provides the latest best practices for product and service development and maintenance. The CMMI models improve the best practices of previous models in many important ways. CMMI is nowadays seen as the standard and benchmark for software process improvement.

CMMI is divided in 5 maturity levels that define the maturity of the organization in terms of the processes it has to develop software:

1. Initial

2. Managed

3. Defined

4. Quantitatively managed

5. Optimizing

\subsubsection{ISO/IEC 15504}

ISO/IEC 15504 is an international standard.

It is the reference model for the maturity models (consisting of capability levels which in turn consist of the process attributes and further consist of generic practices) against which the assessors can place the evidence that they collect during their assessment, so that the assessors can give an overall determination of the organization's capabilities for delivering products (software, systems, IT services).

The purpose of ISO/EIC 15504, likewise CMMI, is to help organizations to improve the way they develop and maintain software.

A working group was formed in 1993 to draft the international standard and used the acronym, SPICE. SPICE initially stood for "Software Process Improvement and Capability Evaluation", but French concerns over the meaning of the last word meant that SPICE now means "Software Process Improvement and Capability Determination". 
Even though the formal ISO standards number, ISO/EIC 15504, is now the correct reference, SPICE is still used for the user group of the standard, and the title for the annual conference. The first SPICE was held in Limerick, Ireland in 2000, "SPICE 2003" was hosted by the European Space Agency (ESA) in Netherlands, "SPICE 2004" was hosted in Portugal, "SPICE 2005" in Austria, "SPICE 2006" in Luxembourg, "SPICE 2007" in South Korea and "SPICE 2008" in Nuremberg, Germany.

The first versions of the standard were focused exclusively on software development processes. This was later expanded to cover all related processes in a software business, for example, project management, configuration management, quality assurance, and so on. The list of processes covered, grew to cover six business areas [ISOIEC2004a]:

- organizational

- management

- engineering

- acquisition supply

- support

- operations

In a major revision to the draft standard in 2004, the process reference model was removed and is now related to the ISO 12207 (Software Lifecycle Processes). The issued standard now specifies the measurement framework and can use different process reference models. There are five general and industry models in use.

ISO/IEC 15504 has been developed by the Joint Technical Subcommittee between ISO (International Organization for Standardization) and IEC (International Electrotechnical Committee).

ISO/IEC 15504 is divided in 6 capability levels [ISO2009]:

0 . Incomplete process

1. Performed process

2. Managed process

3. Established process

4. Predictable process

5. Optimizing process

\subsubsection{SCAMPI}

\subsubsection{Context}

This section provides an overview about the main principles and concepts of the Standard CMMI Appraisal Method for Software Improvement (SCAMPI) used to evaluate the CMMI model.

The SCAMPI method main goal is to identify the strong and weak points of the organization as well as the ratings relative to the CMMI appraisal reference model. It includes the best practices found in the community after many years of improvement of the model and of the assessment method. The SCAMPI method brings knowledge from several other legacy methods. The SCAMPI method satisfies the ARC v1.2 and is a class A appraisal method. 
The Appraisal Requirements for CMMI (ARC) V1.2 defines the requirements considered essential to appraisal methods intended for use with Capability Maturity Model Integration models. In addition, a set of appraisal classes is defined, based on typical applications of appraisal methods [ARC2006]. At this stage only the SCAMPI is the accepted method for evaluating organizations according to the ARC.

The SCAMPI evaluation method is divided in three different classes evaluation, A, B and $\mathrm{C}$. The less rigorous and less costly versions of the SCAMPI method, B and C may be used to develop process improvement plans and (perhaps) to prepare an organization for a full-scale Class A SCAMPI. The class A appraisal is the one that allows an organization to be evaluated against a maturity level being the most extensive and rigorous one [AHERN20005].

\subsubsection{Objectives and characteristics}

The SCAMPI method has the following primary objectives:

- Provide a common, integrated appraisal method capable of supporting appraisals in the context of internal process improvement, supplier selection, and process monitoring.

- Provide an efficient appraisal method capable of being implemented within reasonable performance constraints.

The SCAMPI method has also essential characteristics that distinguish it from other evaluation methods. It is accurate, repeatable, cost effective, provides meaningful results and is ARC compliant.

In terms of accuracy, the method guarantees that the results are truly reflective of the organizations maturity and capability and they can be used to compare organizations that use the same reference model as CMMI. It also brings to its report the weaknesses and strengths of the organization. The SCAMPI method is also repeatable allowing the comparison between organizations that have been conducting the same method guided by different people. Although the method takes some days to complete it is seen as cost effective taking into account the number of hours spent in planning, preparing and executing the appraisal. Another important objective of the appraisal that is also obtained through the SCAMPI method is to allow the sponsor taking decisions on the next steps regarding process improvement and monitoring. The method is also ARC compliant.

\subsubsection{Usage}

The SCAMPI can be used with different objectives but one objective should always be present when deciding how it will be used: process improvement and capability evaluation.

There are 3 main usage modes for the SCAMPI method: internal process evaluation, supplier selection, process monitoring.

The internal process improvement is the use that is mostly given to a SCAMPI. The organizations use the method to baseline their capability level, prepare process improvement programs or to measure and adjust its own process improvement programs. SCAMPI can be an extra tool to support the process improvement program and its processes and tools help to achieve the expected results by the organization.

The supplier selection mode is a very expensive mode of selection of supplier. Usually this is not the only criteria for selecting a supplier. The results are usually used to assess the risk taken to select a specific supplier. They are also used as a baseline for monitoring the processes used by the supplier. 
The SCAMPI method can also be used as a monitoring process. In this case it is usually used in conjunction with the supplier selection mode in order to monitor the processes of the selected supplier. It brings valuable input to make sure the supplier is working on process and brings the supplier key information for process improvement and its priorities. It is important to notice that this methodology stands on long-term relationship between supplier and its customer.

During the implementation of each of the methods there are certain pieces such as planning or reporting that have to be tailored according to the objectives of the assessment.

\subsubsection{Performance}

It is objective of the method to use the minimum of resources and to minimize the impact on the appraised organization's daily work. It is also objective to keep the method as-is to ensure the characteristics that have been stated above.

The SCAMPI method has been based on a set of assumptions and design principles that are important to be understood and will be discussed over the next paragraphs.

To first idea to be passed is goal ratings. They are a function to the level of implementation of the corresponding specific practices implemented in the organization. In CMMI there is a direct reference between both that helps achieving the goals. It is important to have in mind that goals rating can be determined after the study of the corresponding area that is being assessed.

The information gathered for each area is key in determining the achievement of practice implementation. In order to make this decision and judgment it is necessary to evaluate the gathered data to assess it towards the specific and generic practices of the corresponding process area goals. The appraisal team compares the data collected against the practices of the model (including all the model information that is both required, expected and informative) in order to decide which practices are implemented.

The CMMI is a model about what should be done not how it should be done, so the practices described are high-level abstractions of the implementations that take place in the organizations. These implementations at the project and process level are named practice instantiations. Often, implementation of CMMI do not happen at the company level, but on organization level. Inside this organization is the one being appraised and should follow a set of processes and procedures scoping a set of projects to be evaluated. This way of performing the evaluation requires gathering objective evidences of projects and processes so that this analysis can bring a certification to the whole organization.

\subsubsection{Verification and discovery}

The SCAMPI appraisal method can be run in one out of two ways:

- Verification

- Discovery

It is in the best interest of both the organization and the appraisal team to run a SCAMPI appraisal using the verification methodology. Going this way there is sharing of information between both parties and there is a clear view of the evidences available to be appraised organization. This method can be highly effective when there are tools that can help supporting the appraisal process. It leaves to the team the only task for verifying the artifacts and rating the practices according to the model.

The discovery methodology brings us to the world of the unknown in an organization. It requires the appraisal team to go and find out the evidences for each of the practices making it 
much more time-consuming, costly, and error prone as there is no guarantee that the team is always going on the right direction in its discovery.

When using the verification approach the artifacts gathered are available to both parties, the organization and the assessment team. This fact reduces the amount and time of the interviews as well as the need to request more documents. Although when using the verification approach there is already a great part of the documentation made available it is usually needed to request some more pieces of documentation due to inconsistencies in the documentation or in the interviews.

\subsubsection{Types of evidences}

The SCAMPI process describes 2 types of evidences:

- Documents

- Interviews

Documents are written information regarding the model practices, one or more. There are several types of documents that can be used such as organizational policies, procedures, implementation-level artifacts, instruments (e.g., questionnaires) and presentation materials. Documents can be made available via both soft and hard copy, although most of nowadays assessment documentation is in a form of soft copy and accessible via hyperlinks. The interviews are oral conversations with the people using and implementing the processes and projects inside of the organization. Usually they cover a wide-range of roles and resources in the organization such as project managers, managers and engineers. During the interviews there are usually exploratory questions as well as more closed questions. A presentation or demonstration can be used in case it can bring more added value to the process.

The two methodologies of gathering evidences are used in combination in order to better validate the results.

\subsubsection{Investigation}

Due to the large amount of practices and the needed data, the SCAMPI method has to be effective in terms of data collection and data management. It is then crucial to use a concept of optimized investment of resources describe in the SCAMPI method by focused investigation. Essentially, this approach can be described at a top level using the following data collection and investigation paradigms:

- Understand what objective evidence is available, and how it contributes towards implementation of model practices within the appraisal scope.

- Continually consolidate data to determine progress toward sufficient coverage of model practices.

- Focus appraisal resources by targeting those areas for which further investigation is needed to collect additional data or verify the set of objective evidence.

- Avoid unnecessary or duplicated effort that does not contribute with additional information to the achievement of sufficient coverage or toward obtaining significantly greater confidence in the appraisal results. For example, keep interviews efficient by asking questions only about practices for which sufficient data has not already been obtained.

These concepts come from the experience gained over the years on performing appraisals by people all over the world in different environments and with different cultures. They 
combine the need to put more effort where it is needed with mechanisms to accelerate areas where less effort is required. The approach starts with collection and analysis of objective evidences in order to determine the completeness and adequacy of the evidences providing evidence of further information gathering if needed. It is then key to keep track of the existing evidences and start shortening the existing gaps to be covered in terms of assessment. The cycle of identifying as early as possible missing information and requiring it immediately after this need is identified brings repetition to the process making it more effective and guaranteeing success of the assessment in the planned time frame.

\subsubsection{Practice Implementation Indicators (PII)}

There are 3 types of practical implementation indicators that are necessary consequences of implementing the model practices. They are direct artifacts, indirect artifacts and affirmations coming from interviews.

By direct artifact it is understood any output resulting directly from the implementation of a practice, either generic or specific. Some examples of direct artifacts are typical work products stated in the CMMI model, project documents, deliverables, training materials among others.

Indirect artifacts are evidences that are consequence of performing practices but are not purposes for which the practice is performed. This type of artifact usually helps to identify if the practice is performed whenever there are doubts about this fact. Typical work products listed in the CMMI model, minutes, review results, reports, presentations among others are examples of indirect artifacts.

Affirmations are oral or written statements that support or confirm the implementation of the practices. These statements usually come from the implementers of the practices, stakeholders or customers. Examples of these artifacts are interviews, presentations or demonstrations.

\subsubsection{Rating process}

The process of rating mandates that the appraisal team reaches a consensus prior to giving a rating. This process is structured as shown in figure 2.8 . 


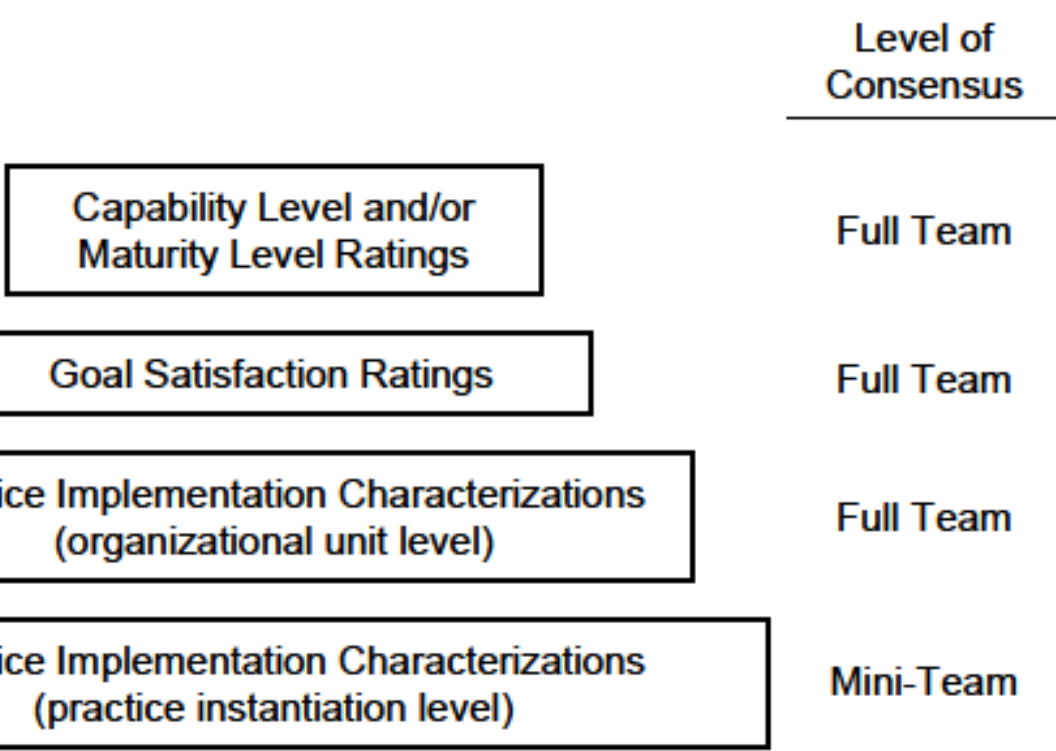

Figure 2.8 - SCAMPI rating process [SCAMPI2006]

The data from all the sources is analyzed in several sessions either in whole team sessions or in mini-team sessions. Mini-teams are usually organized in process areas being the individual roles assigned based on experience, knowledge and skills.

The team members have in their task list the review the objective evidences provided by the organization where they will identify the PII related to each of the reference model CMMI. PIIs are pieces of evidence that a given CMMI Practice (that supports a CMMI Goal) has been implemented as needed in the CMMI model. All relevant findings are recorded as weaknesses or strengths being usually the first findings to be recorded the weaknesses or gaps towards the model.

The verification of PIIs should continue until sufficient objective evidences have been obtained so that characterization of a practice can be marked as complete. The definition of sufficient is translated to enough direct objective evidences have been found and they are supported by indirect artifacts and/or affirmations. The consensus on this is obtained at the mini-team level.

\subsubsection{Practices characterization}

Each practice is characterized with one of the 5 different status [SCAMPI2006]:

- Fully Implemented (FI)

- Largely Implemented (LI)

- Partially Implemented (PI)

- $\quad$ Not Implemented (NI)

- $\quad$ Not Yet (NY)

The appraisal team or the mini-team assigns values to rate the level of implementation of each practice. The objective of this rating is to summarize the assessment of the process area as well as to identify the top priorities in terms of process improvement. After these ratings are set 
and after the values are aggregated, the final ratings are set using the full appraisal team consensus.

It is part of the process to use focused investigation techniques to track progress. It is a key objective to gather the necessary information to rate the process. So that this happen, and during the process of assessment, it might be necessary to review the data-gathering plan in other to collect more information than the initially set.

The ratings are generated for each generic and specific goal within the scope of the appraisal. The ratings can also be generated by process areas, capability levels, or maturity levels if desired by the sponsor. The maturity and capability level ratings are based on the CMMI reference model definition.

The assessment is usually supported by tools that help the assessment team on the collection and presentation of data. These tools can be of various different forms, like questionnaires, surveys or IT applications. Although the SCAMPI method does not require any of these tools, they can help to get deeper insight of the organization in a shorter period of time, making the SCAMPI process more efficient and effective. The large amount of data is a challenge that is always present in SCAMPI evaluation and that can be simplified using these tools.

\subsubsection{Effective team practices}

There are some techniques that can be used in order to enhance the team performance during an appraisal. It is part of the role of the team leader to guide the team to invest their effort wisely and to encourage team practices that bring efficiency and effectiveness. Some of the features that are recommended include the following:

- Virtual meeting technology - Virtual methods such as video conferences, teleconferences, and other similar technologies can be used to help reduce the travel needed to perform an appraisal. However, these methods need to be clearly defined in the Appraisal Plan. Furthermore, it is the responsibility of the appraisal team leader to ensure that the use of virtual methods does not compromise the integrity or accuracy of the appraisal activities or the appraisal results. Virtual methods should allow for adequate interaction between the appraisal team members and the appraisal participants and should provide mechanisms for the appraisal team to control the interactions.

- Emphasis on the verification-based approach - Early identification and provision of documented objective evidence by the appraised organization is emphasized to reduce the extent of data that must be obtained through discovery techniques by the appraisal team during the Conduct Appraisal phase. Too much data that is not useful is just as great a problem as too little data.

- Reduced crafting of findings - In an indicator-based appraisal, greater emphasis is placed on verification of PIIs and there is less need for crafting findings. The appraisal team need not spend time generating findings that simply acknowledge satisfactory implementations or the existence of artifacts, but can focus more on identifying weaknesses or significant strengths.

- Consensus - At the discretion of the appraisal team leader, mini-teams are given the authority to reach consensus on practice implementation at the instantiation level; full team consensus is required for aggregation to the organizational unit level. The characterization of practice implementation can also help facilitate consensus on whether implementations satisfy model intent, either at the instantiation or organizational unit level. The consensus, discussion, and decision-making processes 
used by the appraisal team can bring significant sources of inefficiency if not monitored closely.

- Effective data management - The SCAMPI A method provides ways to collect, organize, and manage appraisal data efficiently, and to facilitate the team decisions that must be made based on the set of objective evidence. The focused investigation techniques described earlier in this section can help keep the team oriented on what objective evidence has been collected, what remains to be collected, and how it will be collected. This process can be greatly enhanced through the use of automated support tools. A thorough understanding of progress toward sufficiency of coverage can help focus data collection. Interviews, in particular, can be shortened by focusing on specific data collection needs.

It is important to notice that several other techniques can be applied in order to improve the performance of the team.

\subsubsection{ISO/EIC 15504 assessment method}

The ISO/EIC 15504 assessment method consists of a set of 7 main activities:

1. Initiation

2. Planning

3. Briefing

4. Data collection

5. Data validation

6. Process attributes rating

7. Assessment reporting

The assessment process begins with the identification of the sponsor, the selection of the team leader who will lead the assessment, the team and the definition of the purpose of the assessment so that the organization knows this is being carried out. The purpose definition should have into account the organization's business goal to be in in line with it [ISOIEC2004b].

The next step would be to define the scope of the assessment including any constraints that might be needed to be applied. The scope should include the processes and the capability level s within the organization to be investigated. It is important to state that the scope can be negotiated as the assessment goes by. Regarding constraints, it is important that they are known by the team and the sponsor as they might cause delays in the process or bring unknown risks during the assessment. These constraints include the availability of resources, the time planned for the assessment, the processes to be excluded from the assessment, the samples size to be gathered, the ownership of the work products or the control of for example confidential information.

An assessment plan describing all activities performed in conducting the assessment is developed and documented together with an assessment schedule. These activities include all activities necessary but may be tailored according to the needs. The schedule must include the resources that do not only comprise people but also equipment and logistics. The plan should also include how the assessment data is collected, recorded, stored, analyzed and presented having the focus on the tool used. This data should also include any extra pieces of information required by the sponsor.

Risks are a very important item to have into account in any project and an ISO assessment is no different. Due to this fact risk factors and mitigation strategies must be documented, 
prioritized, tracked and monitored throughout the assessment. Potential risks may include changes in the assessment team, organizational changes, changes in the scope and purpose, lack of resources, lack of availability of documents, confidentiality, among others.

In order to perform the data collection correctly it is necessary to gather evidences of the process performance and of the process capability of each of the process in scope. Evidences of these include observation of work products and their characteristics, testimony of the process performers and observation of the infrastructure. It is also necessary to record and maintain the references to the evidence in order to support the attribute rating as well as verify the completeness of data to assure there is enough evidence to meet the assessment expectation.

In the process of attribute rating, for each process assessed, a rating is assigned for each process attribute up to and including the highest capability level defined in the assessment scope. The rating is based on data validated in the previous activity. Traceability shall be maintained between the objective evidence collected and the process attribute ratings assigned. For each process attribute rated, the relationship between the indicators and the objective evidence shall be recorded.

The last phase is the reporting and results. During this phase, the results of the assessment are analyzed and presented in a report. The report also covers any key issues raised during the assessment such as observed areas of strength and weakness and findings of high risk. Figure Figure 2.9 shows an example of an organization's capability profile.

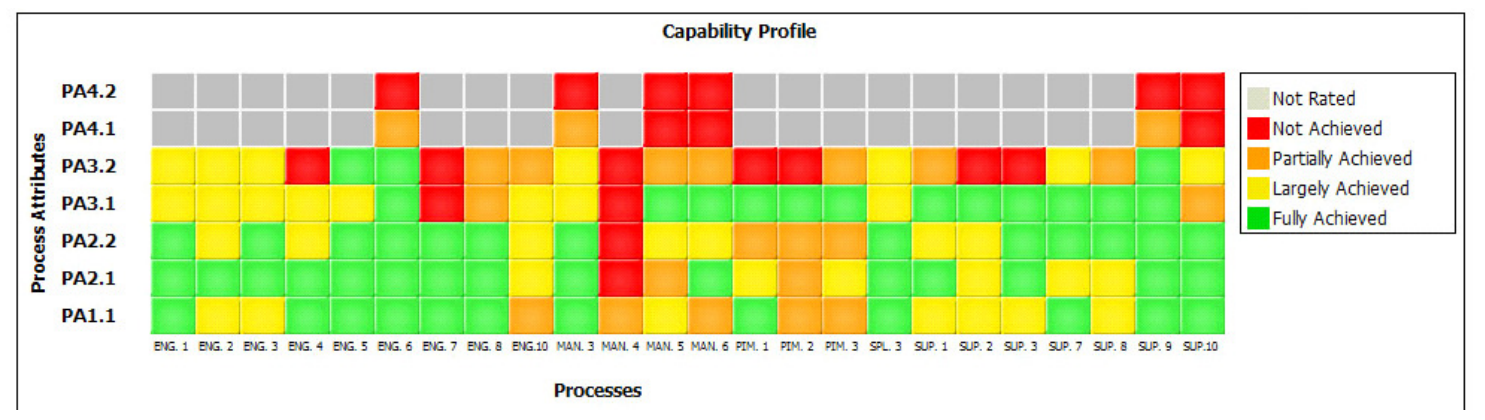

Figure 2.9 - Example of ISO/EIC 15504 capability profile [CAPPRO2009]

\subsection{Conclusion}

TSP has proven to be an effective methodology to achieve good quality products with an impressive improvement in terms of the key variables software development organizations evaluate nowadays. It does not implement cheap techniques, however the price of quality is quickly paid off in a very short time. TSP with its iterative life cycle brings benefits to the organizations that are seen on every cycle due to its ability to force measurements and to use them to improve both the individual and the organization performance.

The SCAMPI and ISO/EIC 15504 evaluation methods studied are not very different from each other. They both assess subsets of the organization, they both have a team making this assessment and they both use interviews and analysis of artifacts in order to gain insight about the organization. When considering the TSP methodology to assess organization, it brings the new people dimension as well as new variables to the assessment equation. It was also possible to verify that the cost to execute any of these methodologies is high, both in terms of external and internal expenditure as it requires time from the internal resources and the external ones.

The analysis done in this chapter to the different technologies and its perspectives contributed greatly to setting up the methodology that is described later in this dissertation. It 
was possible to gain insight about what is done in the most know and used models in terms of evaluation as well as compare that to what TSP does in organizations. The most important areas were the details of TSP, the process for assessing and organization with the SACMPI or ISO/EIC 15504 methodologies and the drawbacks that all face to be more effective and efficient in these processes. 


\section{TSP gap analysis methodology}

\subsection{Method overview}

The TSP evaluation method has been developed having in mind the TSP practices and procedures as well as the usual practices of the industry. It combines also the best practices of the SCAMPI and ISO/EIC 15504 assessment methods.

The method developed to perform the gap analysis collects data from three different instruments. It uses the collection of artifacts, interviews with key people in the organization as well as informal conversations. Conducting this analysis is a complex operation and requires some planning and effective preparation. Figure 3.1 shows an example of the plan for preparing this gap analysis. 
TSP gap analysis methodology

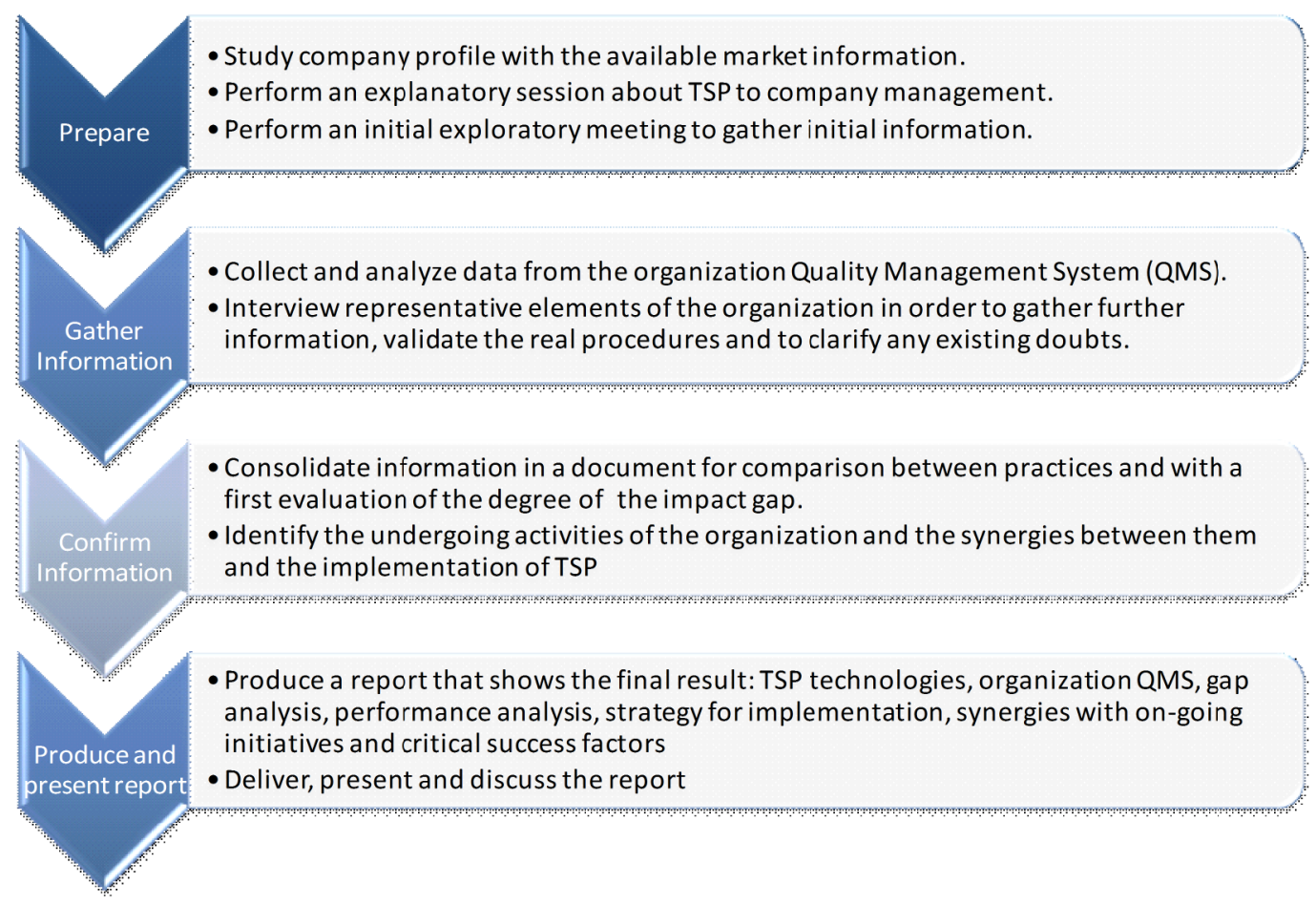

Figure 3.1 - Plan for preparation of the gap analysis

Successful execution of this gap analysis plan depends on having a well prepared and trained team as well as having support from the organization in making available the resources (people and information), for the team to use. These things do not happen by accident, they require a good planning and preparation as well support.

One of the key elements of this process is to avoid using large databases of data but to simplify the use of the available data and to use the interviews to validate the gathered data.

The definition of the organization part to be appraised is also an important factor to have into account. This process can be applied to an whole organization or to a subpart of it, to a business unit, a single project, a group of projects or almost any combination of those. Due to this fact there can be tough decisions on where to focus the gap analysis and on who should be involved.

In case of a software engineering group this gap analysis can be relatively easy to perform as the scope of the team is usually quite clear and understandable, however if we move for example to systems engineering the range of activities can be quite more extensive. Also the boarders get less understandable making the analysis more difficult to perform. When applying this methodology to a quite diverse organization it can also be considered to split the assessment in two or more evaluations in order to group people and tasks as it makes more sense. Another possibility would be rate the different parts of the organization separately so that one part's rating is not damaged by the other. However, the approach that better suits the assessment is to keep it all in one to make sure that the whole organization is aligned as well as to make sure the improvement plan will make the organization more uniform. 


\subsection{Activities}

\subsubsection{Prepare}

The process should start with the investigation by the team about the company that will be analyzed. This investigation can start by going through the web pages of the company (nowadays almost every company has a webpage), looking for articles about the company, its main customers, its industry focus, its structure, among other general information that can be helpful. This information is very important to be used to break the ice with the organization's people besides its technical value

It is key that the organization at its various levels is aware about the what is TSP, its objectives, its methods, its advantages. In order to achieve this it is recommended that a 1-day session is performed in the company premises. The SEI has available a 1-day executive seminar that can be adjusted if needed and that can be a good introductory course to the company's management. The typical schedule is as in Table 3.1.

\begin{tabular}{|c|c|}
\hline Time & Topic \\
\hline $8: 30-9: 15$ & Introduction and introductory exercise \\
\hline $9: 15-9: 45$ & Strategies and principles \\
\hline $9: 45-10: 00$ & Break \\
\hline $10: 00-10: 45$ & The Personal Software Process \\
\hline $10: 45-11: 15$ & Exercise 2: Using data \\
\hline $11: 15-12: 00$ & Building self-directed teams \\
\hline $12: 00-13: 00$ & Lunch \\
\hline $13: 00-13: 45$ & Managing with facts and data \\
\hline $13: 45-14: 15$ & Exercise 3: Schedule management \\
\hline 14:15-15:00 & Building quality products \\
\hline $15: 00-15: 15$ & Break \\
\hline $15: 15-16: 15$ & Exercise 4: Quality management \\
\hline $16: 15-17: 00$ & Putting the TSP into practice \\
\hline $17: 00-17: 30$ & Summary \\
\hline
\end{tabular}

Table 3.1 - Typical schedule TSP introductory course

During this session a lot of valuable information can be gathered about the organization that we are analyzing as there will be questions coming from the audience as well as the team can use the topics described to ask the audience about their processes and procedures. As we have usually different people with different roles in this session and as it is not a formal assessment or interview session a lot of valuable information can be collected informally.

After this introductory session the next step would be to setup an informal meeting with a person that can cover most of the processes and procedures of the company as this person is very likely involved in the whole assessment process. It is very important to have a good relationship with this person as during informal periods like this meeting, a break or a lunch or dinner artifacts can be validated or gathered. 
During this meeting it is important to assess the whole organization development process, to explain the next steps and eventually to adjust these steps as needed. It is very important in case this person is not the organizations manager of the analysts team to involve him or her afterwards in case changes to the plan come from this meeting.

\subsubsection{Gather information}

This is the phase where the team will evaluate the degree of difficulty to gather the artifacts needed for the evaluation. An organization that knows where they stand can be extremely helpful in providing information needed by the assessment team. In this case it will also be easier to conduct the interviews as very likely every resource will know very well where they should stand and the tasks to be performed. If this is not the case it can be painful for the assessment team to find all the needed information. This might make the evaluation last longer, be more expensive and less efficient.

The analysis of the QMS is the first formal task that is going to bring us valuable information. The access to the QMS should be given to the assessment team as well as support by a knowledgeable person of the organization on this subject. There should be at least two periods of analysis of the QMS, one where the analyzer browses the QMS with the help of his support person and another where he does it at his own pace and looks for any evidences that could contradict or verify the previous gathered ones.

There are several key artifacts that the analyzer should be looking for. A list of these can be found in the Table 3.2. However these artifacts can vary according to the information already gathered at this stage.

\begin{tabular}{|c|l|}
\hline Artifact & \multicolumn{1}{|c|}{ Reason } \\
\hline QMS architecture & $\begin{array}{l}\text { This document can give the analyzer a very good } \\
\text { idea about where to find what in the QMS }\end{array}$ \\
\hline Process descriptions & $\begin{array}{l}\text { When looking for process descriptions you } \\
\text { should look for all kinds of processes of the } \\
\text { organizations you are evaluating. }\end{array}$ \\
\hline Project plans & $\begin{array}{l}\text { Project plans can give you a great idea about } \\
\text { following processes and process life cycles as } \\
\text { described in the QMS }\end{array}$ \\
\hline Project lifecycle description & $\begin{array}{l}\text { This document can show you the stages that the } \\
\text { organization takes when developing a product or } \\
\text { providing a service. }\end{array}$ \\
\hline Measurement analysis & $\begin{array}{l}\text { In case it exists this information can be very } \\
\text { valuable to translate to the TSP metrics and take } \\
\text { advantage of the analysis already being done. }\end{array}$ \\
\hline Project Metrics & $\begin{array}{l}\text { Metrics are a key element for TSP. If these are } \\
\text { already being collected it is very worthy taking a } \\
\text { look on these as it is one of the great pieces of } \\
\text { effort in TSP to implement them. }\end{array}$ \\
\hline
\end{tabular}

Table 3.2 - List of artifacts to look for in the QMS 
In immature organizations it can happen that some or all of these are not available anywhere or are very different across the organization being assessed. If this is the case there is a great opportunity to implement from scratch new processes and to implement them as described by TSP.

The last step of gathering information is to perform interviews. During the analysis of TSP and the knowledge of the author of IT organizations three roles have been considered to be the best for interviews:

- A project manager

- A tester

- A developer

One of the reasons to pick only 3 roles is that the process described here is planned as fast and as simple as possible. However, if needed, more interviews can be planned and conducted either looking for the same or new resources.

Project managers are key people in organizations and should have a process to follow. They are the ones that usually bend the rules and break them according to the needs. Also, they can speak about the whole life cycle of projects from tendering through delivering and closing them. Due to their duties, reporting and communication usually goes through them as well as people and team management that play a crucial role in TSP being quite different from the way most of the organizations do it. They are many times people who come from lower ranks in the development chain making them also knowledgeable on the details as for example of developing, analyzing requirements or testing.

On talking to testers and developers we are talking to the lower-end workers in the projects (this does not mean they are less important). They are the ones that should better understand their roles and that can best look for improvements and problems in the process followed and prepared by their superiors in the organization. Testers are many times involved in requirements which can bring a view of the early phases of the life cycle. They are also the ones validating the product developed. TSP advocates the reduction of time of the testing phase and by analyzing this role, the behavior and the responsibilities of testers we can address the TSP changes that are suggested in the process so that the testing phase can be used to its main objective, testing, and not to find an extensive set of errors as it usually happens.

Developers can bring us the view of how a team works in the organization as well as the main tasks of developing a product and how they are distributed. From this interview we can address the TSP self-directed team concept as well as many other concepts that can bring great gains if well performed in this phase such as for example inspections and reviews.

Time and task management as well planning are key activities in TSP. When performing an interview these should always be in the mind of the assessment team as this is an area that can have great impact in the organization and is usually difficult to change.

The questionnaires developed in the scope of this dissertation can be found on the chapter 3.9 and they are key elements of this work. It is very important that after each of the interviews the questionnaires are updated and improved as this information can be very helpful to tune the gap analysis process.

\subsubsection{Confirm information}

The stage of confirming information starts with the consolidation of the information gathered. This consolidation should have into account the end results matrix assessment as it is objective of this consolidation to prepare an intermediate document to be shown to the 
management of the organization. On performing this consolidation, besides the objective previously stated, there is the need of finding the further gaps of information for the next iteration of meetings with the organization. This missing information for the assessment should be gathered immediately after presenting the consolidated report.

There are many reasons why this intermediate presentation is done. It brings the validation of the assumptions and pre-evaluation of the work that is being done in a more informal environment than the final presentation.

Two documents should start to be produced at this stage:

1. The intermediate presentation document, as it has to be presented to the customer and is a valuable input for the final presentation.

2. The final report, specially the introductory parts where the organization processes are described and very little can change due to further meetings.

Although agendas can change and should be adapted according to the organizations, hereby follows a suggested one:

- Introduction and plan - This section should present an introduction to the work being done, the methodology being followed, the objectives of the work and the next steps planed to complete the gap analysis.

- Main conclusions - In this section the main conclusions found as well as the open items so far should be presented and the objective of this part of the presentation is to validate the conclusions with the team that is managing the project on the organization side. In case there are disagreements between the assessment team and the organization artifacts should be presented by both sides in order to reach an agreement. It is important that a consensus is reached at this stage as in case it is not the same discussion will come again in the final presentation in a more formal and hostile environment.

- Current gaps - This section presents in detail each of the gaps that has been identified so far. Again, as in the previous section in case of disagreement a consensus should be reached. It is very important that the assessment team can prove each of the gaps either through artifacts or referring to the interviews that have taken place in case there are disagreements.

- Next steps - The next steps of the work should be presented here. In case there is the need of more information either through interviews or analysis of artifacts this should have been planed beforehand in order to try to collect the needed information in one visit (the same that includes the intermediate presentation session) so that the organization does not invest too much time in this exploratory process.

In case the organization is ready for further discussions on planning the implementation, a suggested discussion agenda can also be pat of the meeting:

- High level project planning including selection of teams and projects - If the organization is sure that wants to implement TSP, this step is very important in order to speed up the process. This should be a constructive discussion between both parties about when the TSP projects can start, who is going to be involved, training plans, among other tasks.

- Next steps - In this section the tasks that have been agreed should be summed up and taken by both parties

During this visit and in case it was detected some lack of information further interviews or collection of artifacts might be needed. This should be aligned with the organization manager of 
the project. In case a new stakeholder should be interviewed or a previously stakeholder is interviewed new questionnaires should be produced or the existing ones updated.

\subsubsection{Produce and present report}

The final report and presentation are key elements to show organizations where they are when compared with the TSP practices. A proposed version of this report is shown in section 3.10 .

This final presentation should be an enhanced version of the intermediate presentation and a similar structure should be followed. It is key to make sure the presentation and the report delivered are consistent and it is advisable that the report is delivered before the presentation meeting so that the organization has time to study it prior to the discussion.

The discussion of the report and the presentation conclude the gap analysis and a further version of each of these documents might need to be issued in case there are disagreements in the documents and an agreement is reached in this meeting.

After this it will be up to the organization to decide what to do, to implement or not to implement TSP.

\subsection{Success factors}

There are several key success factors that need to be taken into account when executing the evaluation:

- There must exist commitment from the organization to perform this process, if not there are high risks that a good end is not reached or that the evaluation results are not reliable. In this area it is included the availability of the resources that is a very important element to collect the needed information.

- Motivation to perform this gap analysis is key. Without it, people involved in this assessment will not perform well and information gathered will not be reliable resulting in results that are not correct.

- The planning has to be done prior to the evaluation and has to be approved by all the key stakeholders. Only this way we guarantee deliveries and milestones to be followed.

- The assessment team has to be experienced and knowledgeable, giving the organization guarantees that work is being well done and that the assessment team can help solving problems found during the work being performed.

- No information should be hidden from the assessment team and communication should be open and fair with the organization. This touches the first point in this list, however due to information being a key element to perform the analysis it is stated here as a standalone point.

- The organization has to be ready to accept the evaluation done by the assessment team, not raising non-existing issues in the end or during the evaluation in order to challenge the work being done by the team.

In case any of these fail to happen, issues might arise during the evaluation and the results of the evaluation might not reflect the reality of the organization. 


\subsection{Constraints}

The team always prefers to have full control of the appraisal, however this is not always possible and the assessment must still be done in the world we have. There might be constraints that affect the gap analysis because, for example we have to meet a deadline for the project that is being assessed or there are some resources on sick-leave. Usually setting up a plan for the analysis as well setting up goals in this plan can be a good incentive to find valuable workarounds for these constraints.

Holidays, cultural differences and human resources policies can make the process of evaluation more difficult. As examples performing an appraisal during Ramadan or Christmas can bring extra difficulties as well as mixing teams of Latin and Nordic resources might bring some misalignments on the work cultures. Once again all these constraints can be taken into account and planning can help mitigating these extra risks.

\subsection{Risks}

Running an analysis on an organization always brings risk to the ongoing activities. These risks should be identified and mitigated regularly as the analysis goes on, specially when there is a high pressure to have it completed in a very short period of time. Management (including top-management), must be aware of these issues.

One of the main risks that can happen is the difficulty in gathering the needed artifacts from the tools that the organization uses. In less mature organizations this risk gets higher as there might be practices that are implemented and would need minor changes, however, due to the lack of knowledge of some resources or lack of centralized information these practices can be tagged as not performed.

There is also the risk of the time taken to perform the evaluation be longer than expected. This might come from having an unexperienced assessment team or by having a very closed evaluated team that is not very keen in making the information available. Top management can be a key stakeholder to break through this risk.

The third very common risk is the one the organization is not very happy with the results that are published and discussed. This risk can be mitigated by having a clear explanation session about TSP that can also be used as the first point of contact to start collecting informal information.

\subsection{Assessment approach}

The assessment of the organization can take 2 routes: the self assessment or the independent assessment.

A self-assessment is carried out by a team in the organization to assess the capability of the organization's own processes. The form of assessment has the advantage of being less formal and usually carried out faster than the independent one, however it is much less reliable. It requires that the skills needed to perform this assessment to exist inside of the organization.

An independent assessment is an assessment conducted by an external party to the organization. It makes the assessment more formal, usually longer and more strict as the independent team is more free. 
The context, purpose and scope of the gap analysis are the key elements to have into account when deciding which assessment to choose.

\subsection{The team}

The team to perform this analysis should have between 2 and 3 people. The reason for avoiding teams of one person is to make sure that there is no information lost during interviews and information verification as well as to be able to inspect and review each other's work.

The team analysts should be persons that are well accepted by the organization that is being evaluated. This will bring confidence to all the relevant stakeholders involved in the evaluation.

Besides these key elements there are other skills that the analysts should have:

- Knowledge of the process

- Skills in TSP

- Communication skills

The knowledge of the process can be obtained by studying and applying the concepts of this document.

The skills in TSP can be acquired in several ways. There are many books on this subject (some of them stated in the references of this dissertation). The SEI website http://www.sei.cmu.org has also many papers and technical reports on this subject [SEI2009a]. There are also courses on TSP which details can also be found on the SEI website.

Communication skills are very important in order to create empathy with the resources in the organization. They can be very helpful on gaining trust from people and understanding the organization. As this is a very broad topic and outside of the scope of this dissertation it will not be covered.

\subsection{Analysis perspectives}

An analysis perspective has been developed based on the TSP methodology and on the author's knowledge of the industry. This is shown in Table 3.3. 
TSP gap analysis methodology

\begin{tabular}{|l|l|}
\hline \multicolumn{1}{|c|}{ Perspective } & \multicolumn{1}{c|}{ Description } \\
\hline Performance & $\begin{array}{l}\text { Analysis of organization performance against the typical } \\
\text { performance in organizations that implemented TSP. }\end{array}$ \\
\hline Teamwork & $\begin{array}{l}\text { The practices associated with the team organization, } \\
\text { involvement and empowerment. }\end{array}$ \\
\hline Measurement & $\begin{array}{l}\text { Framework of measures used on all organization activities: } \\
\text { project management, engineering management and organization } \\
\text { management. }\end{array}$ \\
\hline Quality Management & Instruments and processes used for the quality management \\
\hline Project Management & Practices associated with project management \\
\hline Engineering & $\begin{array}{l}\text { Practices associated with engineering (except verification and } \\
\text { validation). }\end{array}$ \\
\hline Verification and Validation & Practices associated with verification and validation. \\
\hline Process Management & $\begin{array}{l}\text { The quality management system framework and its } \\
\text { management. }\end{array}$ \\
\hline
\end{tabular}

Table 3.3 - Analysis perspectives

Each perspective is divided into several topics. To each topic an evaluation is made considering:

- Benefits associated with the implementation.

- Effort necessary to the implementation.

For the evaluation it is proposed a scale from 1 to 3 :

- 3 - Large benefit - There is little or no evidence of achievement of the defined attribute in the used process.

- 2 - Medium Benefit - There is some evidence of an approach and some achievement of the defined attribute however benefits can still be gained by implementing TSP practices.

- 1 - Small benefit - There is evidence of a complete or systematic approach and a significant coverage of the attribute.

\subsection{Questionnaires}

Questionnaires are key elements to make sure that nothing is forgotten during the interview process. They have a set of guidelines as described in section 3.9.1 to make sure the environment is suitable for information gathering and that as much information as needed is collected. Each questionnaire is also divided in two parts, one with open questions whose main purpose is to let the interviewed person speak and a closed questions section where certain pieces of information need to be collected. 
TSP gap analysis methodology

\subsubsection{General guidelines for the interview}

- The beginning of the interview must be made in a quiet and relaxing environment. Questions should be made as a normal conversation and not as a formal interrogation. Some praises should be made when appropriate in order to gain the confidence of the person.

- The aim should be that the interview is driven by interviewed specially in the beginning of the interview. The goal is to understand the top of mind of the organization regarding what can be improved.

- During the most of the interview the assessment team should listen, should never interrupt the interviewed person, should let him speak till the end and leave a short time (seconds) between sentences so that there is time for the interviewed to continue.

- If during an answer the interviewed references several topics without giving enough information, these topics should be readdressed by the assessment team during the interview.

- The interview time is controlled. From approximately the middle of the interview it is important to start directing the interview to the closed questions and to important topics that haven't been addressed.

- During the interview acronyms should be avoided.

- For note taking paper or a recorder (if previously allowed) should be used. The use of a computer is less efficient and can distract the interviewer.

- During the interview new questions and tips should be noted so that the process can improve.

\subsubsection{Project Manager}

\subsubsection{Open questions}

1. What are the strongest points of your organization regarding project management?

2. What are the improvements that you have seen over the last years?

3. How did the organization evolved over the last years?

4. Which aspects can be greatly improved in project management?

5. Can you describe a typical day of a project manager?

\subsubsection{Closed questions}

Planning

1. How is the planning of a project done (development lifecycle, planning time, ...)?

2. Who is involved in this planing (top management, the whole team, ...)?

3. What is the input for the project planning?

4. How are estimates done for each of the project phases (metrics, past experience, ...)?

5. How are tasks described? 
6. What is the task granularity?

7. Is there any tailoring of the planning?

8. How is this tailoring decided?

9. What are the variables to have into account on this tailoring?

10. Are there inspections done during planning (when are they done)?

11. Which work products are inspected?

\section{Reporting}

1. How is the project monitored and controlled?

2. What kind of reporting exists during the project?

3. How often are they produced?

4. Who prepares the documents?

5. To whom are they addressed?

Tools and Metrics

1. What tools exist to help the project manager?

2. Which metrics are registered in these tools (time per task per resource, time spent in meetings, time spent solving conflicts, measurement of the project progress, ...)?

3. Which granularity is applied to these metrics (days, hours, ...)?

4. Are there any other metrics registered?

5. Are there any tools to keep the project repository?

6. Which information is kept?

7. Who keeps it?

Inspections

1. Which inspections are planned from day 1 and during the project life cycle?

2. How is planned the time for each inspection?

3. Which kinds of inspections are done?

4. What are the goals of these inspections?

5. Who does them?

6. What are the inputs?

7. And the outputs?

8. Are there any tasks that are part of the outputs?

9. How are classified the defects found?

Meetings

1. Are there any regular meetings?

2. Which ones?

3. How long are they?

4. Who are the stakeholders? 
5. What are their goals?

Documents

1. Which documents support the project management?

2. What are the input and output documents?

3. Who is responsible for them?

4. Are there any automatically produced documents?

Roles

1. Are there any well defined roles in the project?

2. Which ones?

3. Who defines them?

4. Who assigns people to roles?

\subsubsection{Tester}

\subsubsection{Open questions}

1. What are the strongest points of your organization regarding testing?

2. What are the improvements that you have seen over the last years?

3. How did the organization evolved over the last years?

4. Which aspects can be greatly improved in testing?

\subsubsection{Closed questions}

Planning

1. How is test planning done?

2. Who is responsible for the test planning?

3. When (development phase) is test planning done?

4. Who is involved in this planning?

5. What is the input for the planning (requirements documents, design documents, ...)?

6. Is there any tailoring in the test planning according to the project?

7. How is this tailoring decided?

8. What are the variables to have into account in this decision?

9. Are there any inspections in the planning process?

10. In which work products are these inspections done?

11. How is estimated the needed time for testing?

12. Is there any post-mortem after the planning?

Tools and metrics

1. Which tools exist to help the tests? 
2. Are there any tools to register the defects?

3. Which metrics are registered in these tools (time per task per person, time to solve an incident, ...)?

4. Which granularity is applied to these metrics?

5. Are there any other metrics registered?

6. Is there any defect classification (type, priority, ...)?

7. Are there any reporting documents produced and used?

Test execution

1. Which test phases exist (system test, integration test, user acceptance test, unit test, ...)?

2. The people who run the tests in each of the phases are the same or different?

3. Who manages each of the test phases? Can someone manage two or more test phases?

4. What is the objective of each of the test phases?

5. Is there traceability between the requirements and the tests?

6. Are there inspections in any step of the test phase execution?

7. In which work products are these inspections done?

8. Is there any methodology used when executing the tests?

9. Which kind of tests are done (regression, stress, ...)?

10. Are there any automatic tests?

11. Which tools are use for this?

Meetings

1. Are there any regular meetings?

2. Which ones?

3. How long are they?

4. Who are the stakeholders?

5. What are the meeting objectives?

Documents

1. Which documents support the testing phase?

2. What are the input and output documents?

3. Who is responsible for them?

Roles

1. Are there any well defined roles in the test cycle?

2. Which ones?

3. Who defines them?

4. Who assigns them to the team? 


\subsubsection{Developer}

\subsubsection{Open questions}

1. What are the strongest points of your organization regarding developing?

2. What are the improvements that you have seen over the last years?

3. How did the organization evolved over the last years?

4. Which aspects can be greatly improved in development?

\subsubsection{Closed questions}

Planning

1. How is the development planning done?

2. Who is responsible for the planning of the development?

3. In which project phase is the development planning done?

4. Who is involved in this planning?

5. What is the input and output of the planning (requirements, resources, design, ...)

6. How are the estimates done (days, hours, previous metrics, experience, ...)?

7. Is there any tailoring in the development planning according to the type of project?

8. How is this tailoring decided?

9. What are the variables to have into account in this decision?

10. Who does the tasks drill down?

11. What is its granularity?

12. Are there any inspections planned in any of the development lifecycle?

13. Which work products are inspected?

14. Are the unit tests part of the plan?

Tools and Metrics

1. Which tools exist to help the developer?

2. Which metrics are registered in these tools (time per task, time spent in meetings, time spent running unit tests, time spent doing detailed design, size of the code produced, time of rework, ...)?

3. Which granularity is applied to this measurements (days, hours, ...)?

4. Are there any other metrics registered?

\section{Process}

1. What are the documents and actions that the developer receives? From whom?

2. What are the products and documents that the developer produces and has to deliver? To whom?

3. Is there any detailed design?

4. Who does it? 
5. Who is responsible for it?

6. Is the developer responsible for any other design?

Code

1. Are there any code standards?

2. Where are they defined?

3. How are they communicated to new employees?

4. Is there reuse of code?

5. How is the reuse decided?

6. Who decides the reuse?

7. Does the developed do a self-revision of its own code?

Unit tests

1. Are there any unit tests?

2. Who specifies them?

3. When are they specified?

4. Is there any registering and classification of defects?

5. What is the classification of defects done (type, phase, ...)?

Inspections

1. Which kind of inspections are done to the developer's work?

2. What are the objectives of these inspections?

3. Who does them?

4. When are they done and what is its periodicity?

5. What are the inputs

6. What are the outputs?

7. Which tasks are set after these meetings?

8. How are the defects found classified?

Meetings

1. Are there any regular meetings (management, post-mortem, with the team leader, with the project manager, with the project team, with other teams, ...)?

2. Which ones?

3. How long are they?

4. Who is involved in them?

5. What are the goals?

Documents

1. Which documents support the development (design, checklists, ...)?

2. What are the input documents needed to the developer and the output documents produced by the developer? 
3. Who is responsible for them?

4. Are there any automatically produced documents?

Roles

1. Are there any well defined roles in the development lifecycle?

2. Which ones?

3. Who defines them?

4. Who assigns them?

\subsection{Report template and example (RTE)}

In this section it is suggested an index on what should a gap analysis report contain. The first subsection will only show the index itself while in the next sections an example of certain sections is provided including an example evaluation of a company.

\subsubsection{Report index}

1 Executive Summary

2 Objectives

3 Methodology

4 TSP

5 The Organization

6 Gap Analysis

7 Performance Analysis

8 Plan for implementation

9 Critical success factors

10 Conclusion

The index described covers the whole lifecycle of the gap analysis done, starting with a description of the objectives, methodology and a chapter about TSP. This initial sections are the introduction to the report.

The next section covers the details of the organization as it was perceived and discussed during the gap analysis so that the whole report can be understood. The following chapters, Gap Analysis and Performance Analysis are the results of the assessment done in the organization. These chapters are placed in an order to be clearly understood in the context.

The last 3 chapters, Plan for Implementation, Critical Success Factors and Conclusions detail the next steps to be taken in order to implement TSP in the organization.

The next chapters present a template as an example as it is believed to be better understood this way. 


\subsubsection{Gap analysis (RTE Section 6)}

The gap analysis was executed against the methodology defined in Section Error: Reference source not found, which included interviews and meetings with the relevant stakeholders, and also the analysis of the QMS of the organization.

\subsubsection{Analysis Perspectives}

The detailed analysis was divided into eight main perspectives with several topics associated to each of the perspectives (Table 3.4). These perspectives have some degree of overlapping which allow a more clear view of the main concepts associated with TSP. For that reason the perspectives should not be analyzed separately. The performance perspective will be analyzed on the next chapter.

\begin{tabular}{|l|l|}
\hline Perspective & Description \\
\hline Performance & $\begin{array}{l}\text { Analysis of company's performance against the typical performance } \\
\text { in organizations that implemented TSP }\end{array}$ \\
\hline Teamwork & $\begin{array}{l}\text { The practices associated with the team organization, involvement } \\
\text { and empowerment }\end{array}$ \\
\hline Measurement & $\begin{array}{l}\text { Framework of measurement utilized on all organization activities: } \\
\text { project management, engineering management and organization } \\
\text { management. }\end{array}$ \\
\hline Quality Management & Instruments and processes utilized for the quality management \\
\hline Project Management & Practices associated with project management \\
\hline Engineering & $\begin{array}{l}\text { Practices associated with engineering except verification and } \\
\text { validation }\end{array}$ \\
\hline Verification and Validation & Practices associated with verification and validation \\
\hline Process Management & Practices associated with the management of processes \\
\hline
\end{tabular}

Table 3.4 - Gap Analysis Perspectives

Each perspective was divided into several topics. For each topic an evaluation was made considering the following:

- Benefits associated with the implementation

- Effort necessary to the implementation

For the evaluation it was considered a scale from 1 to 3 :

1. Large benefit

2. Medium Benefit

3. Small benefit

For the performance perspective only the benefits evaluation is considered due to the fact that it is a consequence rather than a change of processes of the implementation of the TSP practices. 


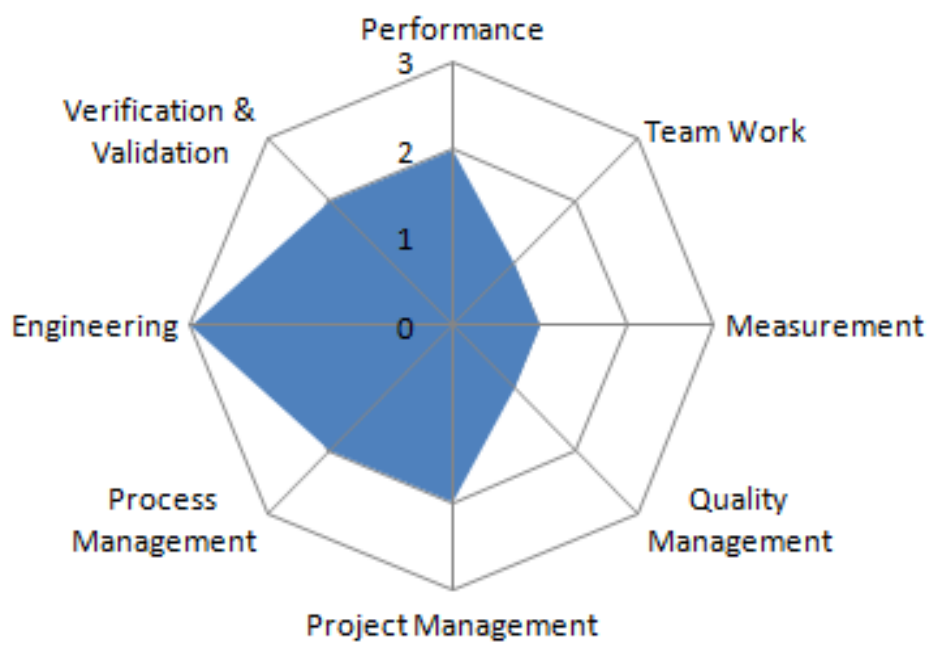

Figure 3.2- Effort Evaluation - The lower values in the graph show higher gaps

The results show that the main gaps are within the teamwork, measurement, quality management, project management and performance perspectives.

\subsubsection{Detailed results}

This section is divided into topics according to the analysis made. For each topic there is a brief description of the TSP practices, the current organization practices (in blue color) and the identification of organization on-going efforts. At the end of each topic the specified effort evaluation is made.

\subsubsection{Teamwork}

The teamwork perspective was divided into two topics: self directed teams and coaching/training. This is due to one of the fundamental aspects of the TSP principals which address the behavior of teams.

Self directed teams - TSP advocates that for the achievement of an excellent performance the team must build a strong sense of commitment. This commitment is built because there is a strong participation of all team members in the planning process - Launch Process - and also because during project execution all the team members are planning, monitoring and tracking their own work and performance. Another important factor for this commitment is the increase of responsibilities of each of the team members, that accumulate a traditional role (developer, tester, analyst, etc.) with a management role (e.g., Configuration Manager, Quality Manager, etc,).

In the organization the developers are taken into account on the planning period but they do not participate with an active role in the planning and monitoring of the project - this role is strongly linked with the project manager $\rightarrow$ Impact Classification: Large Benefit [1].

Coaching and training - TSP states that to achieve the best performance and evolution of a team a coach is necessary. A TSP coach works with the team and the team leader to help the team to collect and analyze data, follow the process defined by the team, track issues and risks, 
maintain the plan, track progress against goals (especially the team's quality goal), and report status to management.

The objectives of the coach are to motivate superior performance, insist on a dedication to excellence and support and guide individual and team development.

In the organization there is no formal role for the performance of these tasks. A light version of coaching takes place within the project but not with a statistical approach $\rightarrow$ Impact Classification: Large Benefit [1].

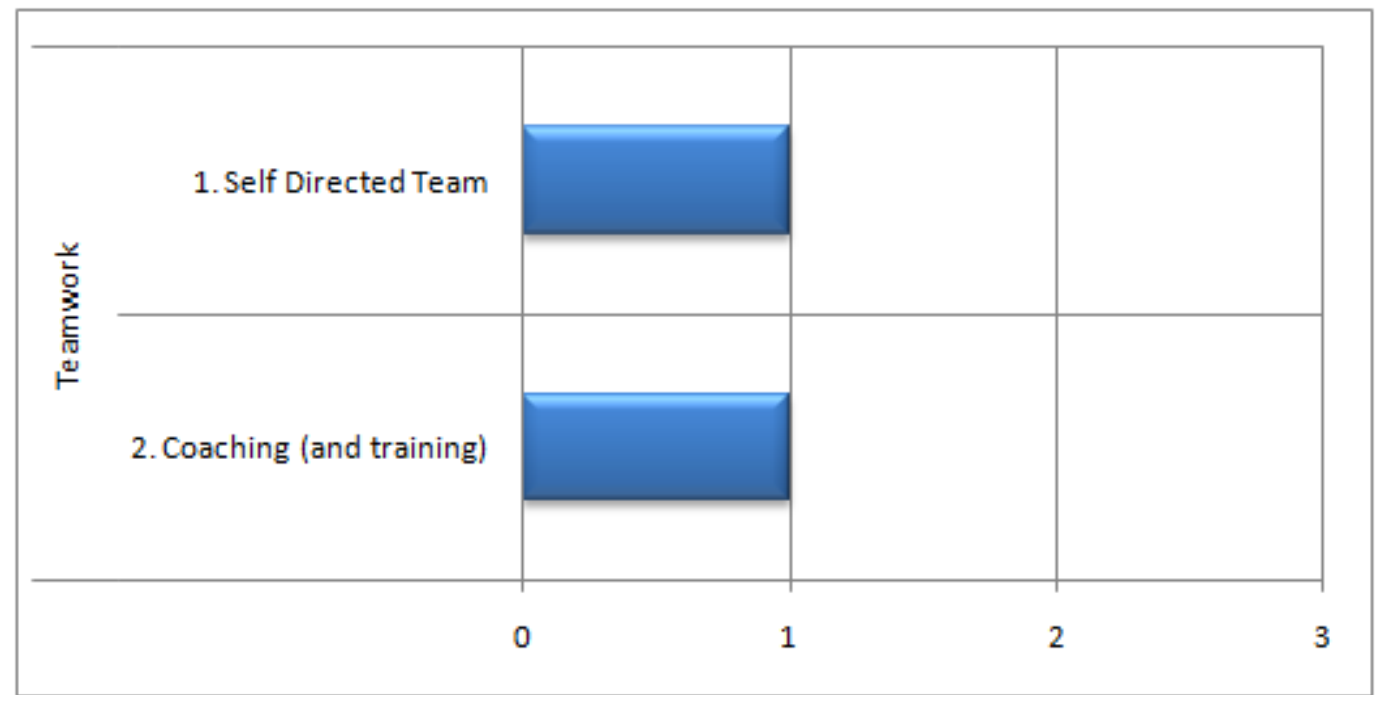

Figure 3.3 - Teamwork Evaluation

\subsubsection{Measurement}

The measurement perspective was divided into five topics: measurement framework, defect, time, progress and size measurement.

Measurement Framework - The TSP has a very strong toolset of measurement which includes:

- Four base measures: schedule (date completed), time, size, and defects

- Dozens of derived measures

- Benchmark data (defects/KLOC, LOC/hour, etc.) for decision making and prediction

An also include some unique features:

- Collection and use of measures at the personal level

- Emphasis on quality metrics

The metrics are detailed, but scalable, and readily support summaries as well as information drill-downs, e.g. system, sub-system, component, object, process, phase and period.

At the present time the organization is using only a few measures: Total task duration (Actual/Plan) and Total defects found in testing. Time and defects are not correlated with size $\rightarrow$ Impact Classification: Large Benefit [1].

Defect measurement - According to TSP defects are recorded during all phases of the software development process, including personal reviews, inspections, design phases and unit 
testing. The defects are classified according to the Orthogonal Defect Classification (ODC) and there is information about the phase where each defect was injected and removed. ODC is a for to capture the semantics of each software defect quickly. With this definition it is possible to make mathematical analysis and modeling possible thanks to the capture of the defect attributes. The analysis of data can bring information about the maturity of the product [IBM2002].

The organization at the present moment only records defects at the validation phase. There is no standard way for classifying the defects $\rightarrow$ Impact Classification: Large Benefit [1].

[Organization's on-going work] The organization has started and initiative to classify the defects within the ODC framework.

Time measurement - With TSP all activities which are planned must have an on-line time tracking. This time tracking must reflect the phase and type of the work being produced (e.g. if a developer is developing code for correcting a defect he must register the time as developing correction). The on line time tracking provides each person a tool for gaining individual awareness of the effective time being spent on each task.

At the organization level time is recorded on a basis ranging from daily to weekly according to the person, team or project. Time records made on a weekly basis tend to be very inaccurate. Since the task granularity can be very high it is not possible to identify with accuracy the exact work being produced (e.g. coding or defect correction) $\rightarrow$ Impact Classification: Large Benefit [1].

Progress Measurement - TSP advocates that only when the task is completed it is supposed to be reflected on the progress status. Since TSP advocates a fine and consistent degree of granularity on the project task definition this method provides a more accurate visibility of the project status (e.g. it avoids the perpetual $90 \%$ completion of tasks).

The organization determines the task completion by empirical observation on project meetings, typically on a weekly basis $\rightarrow$ Impact Classification: Medium Benefit [2].

Size Measurement - TSP clearly defines that the work effort should be measured in effort and size in order to allow a correlation of measures. According to the work being produced several types of measures can be taken in to account (e.g. lines of code, classes, functions, pages, interfaces, etc.). The measurements collection should be as much automated as possible.

The organization does not use size measurement as base measure $\rightarrow$ Impact Classification: Large Benefit [1].

[Organization on-going work] Some projects in the organization are collecting the size measures for very simple statistical analysis. 
TSP gap analysis methodology

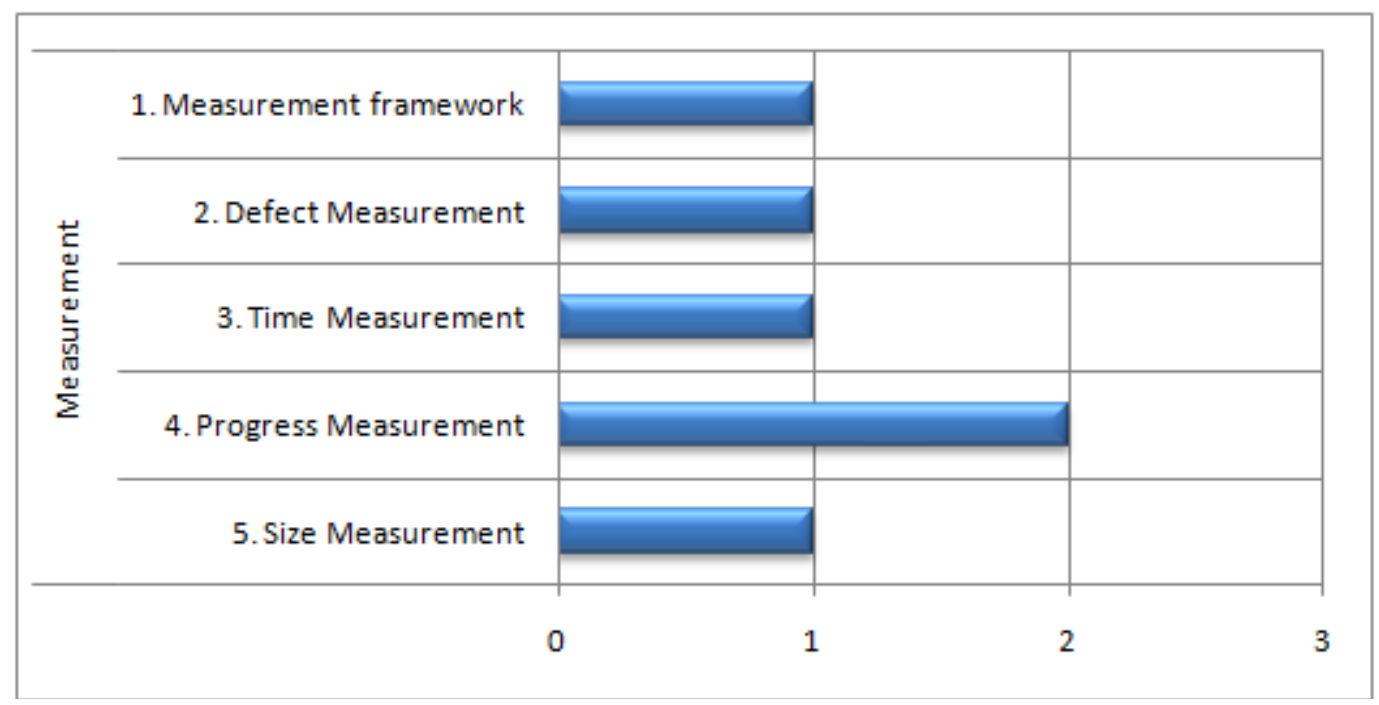

Figure 3.4 - Measurement Framework Evaluation

\subsubsection{Quality Management}

The Quality management perspective was divided into three topics: quality tracking and monitoring, quality planning and quality criteria.

Quality tracking and monitoring - As previously stated TSP provides a complete tool set for quality management. For tracking and monitoring there are derived product quality measures: total defect density, test defect density, percent defect free, among others. And also derived process quality measures: phase yields, review rates, defect removal rates, quality profile (design time, code review time, design review time, unit test quality and compile quality) and corresponding process quality index, among others.

Currently the organization does not have any defined process for quality tracking and monitoring. There is a simple semaphore which controls the adherence of the projects to the defined processes - "on quality" $\rightarrow$ Impact Classification: Large Benefit [1].

Quality planning - Within TSP a quantitative quality plan is derived from the quality criteria and project characteristics (namely estimated artifact sizes and development effort). It includes expected values for items presented in the quality criteria, expected defects injected and removed per phase (derived from size estimates, yields, etc.), expected productivity, expected reuse ratio, time and resource estimates for verification and validation activities (based on yields, size, etc).

The organization defines at the beginning of each project a quality plan tailored to the specific characteristics of the project. The tailoring guidelines are defined on the QMS - these guidelines, do not include the definition of quantitative quality objectives for the projects $\rightarrow$ Impact Classification: Large Benefit [1].

Quality criteria - TSP defines a set of standard goals ( $\mathrm{min} / \mathrm{max} / \mathrm{recommended)} \mathrm{for} \mathrm{the}$ development process: percent defect free, defect densities, development time rates, review and inspection rates, defect injection and removal rates, phase and process yields, etc. It combines process (e.g. review rate) and product (e.g. percent defect free) attributes. Quantitative entry/exit criteria for each process phase are derived from the quality goals (e.g. if significat amounts of defects are found at the unit testing phase then the specific module should be re-inspected). 
At the present time the organization does not establish any type of process or product quality criteria. There are some criteria for conducting specific processes (e.g. peer reviews), that are more related to the rules of functioning than criteria for driving the process $\rightarrow$ Impact Classification: Large Benefit [1].

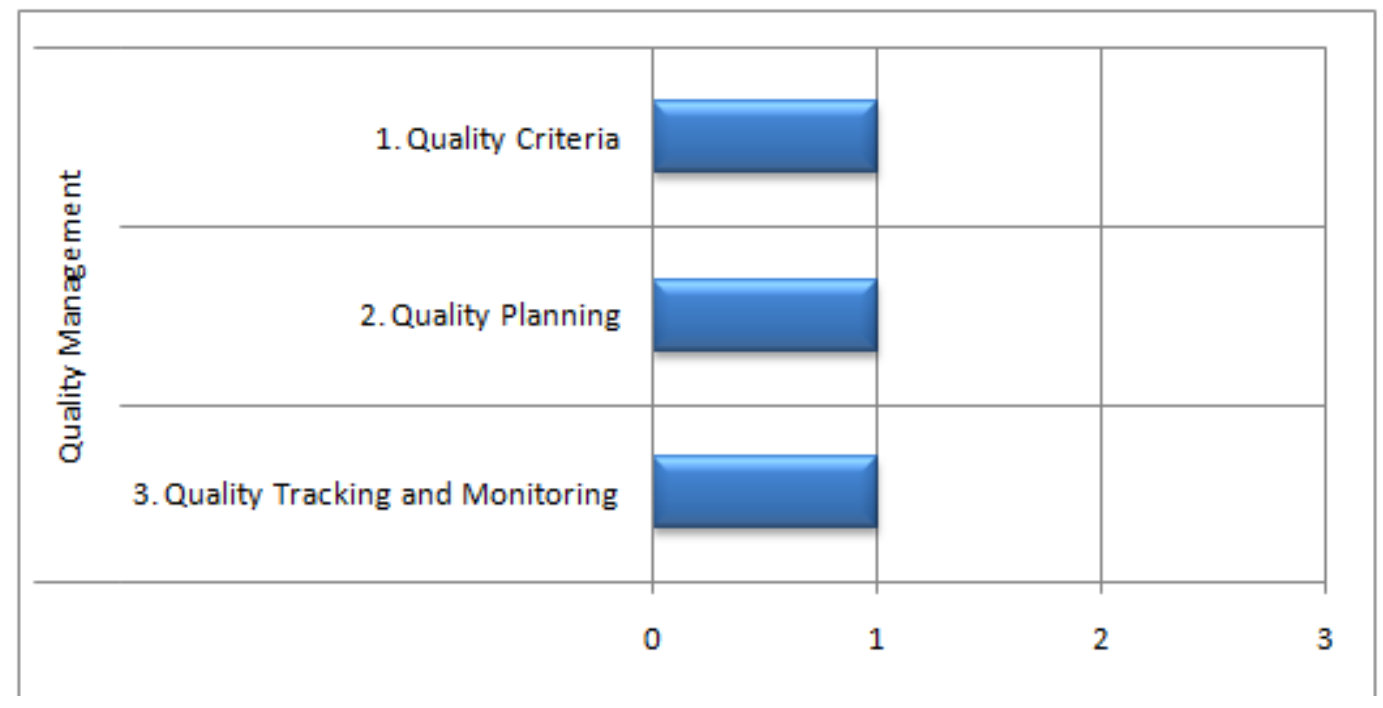

Figure 3.5 - Quality Management Evaluation

\subsubsection{Project Management}

The project management perspective was divided into eight different topics, grouped by phase:

- Planning - Iterations, task granularity, estimation and scheduling, roles and launch process

- Monitoring - project meetings and reporting

- Closing - postmortem analysis

Planning - Iterations - TSP allows a tailored cycle process with several iterations (phase or cycle), where each iteration can have one or more typical phases of the software developing process (e.g. inn a project we can define two major iterations: the first one only with the requirements definition and the second one with the full cycle). The plan is refined at the beginning of each iteration.

The organization typically works on a waterfall model without being prohibitive and allowing the tailoring according to the project needs $\rightarrow$ Impact Classification: Low Benefit [3].

Planning - Task granularity - TSP prescribes that the granularity of tasks should be as refined as possible. Typically the size of tasks can vary between a few hours to a few days (ideally, there should be a minimum of 2 or 3 task per week ).

The organization defines the granularity of each task according to the project and the project manager. There are no rules or guidelines for the granularity and the smallest task is measured in days $\rightarrow$ Impact Classification: Large Benefit [1].

Planning - Estimation and Scheduling - TSP considers the use of the proxy-based estimation (PROBE) method. This method combines the division of a system into parts (e.g. Classes, tables, pages), and the comparison with historical data. Within the estimation size and 
time effort are used in a correlated manner. The scheduling is provided automatically allowing adjustments according to resources. PROBE is an estimating process used to estimate size and effort.

The process for estimation in the organization is based on expert judgment and without correlation with size $\rightarrow$ Impact Classification: Large Benefit [1].

Planning - Roles - The TSP defines a standard set of roles which should be divided among the developers, but can be accumulated according to the size of team or nature of the project. These roles include eight management profiles: Team Leader; Planning Manager; Quality Manager; Process Manager; Customer Interface Manager; Design Manager; Implementation Manager; Test Manager and Support Manager. These roles are accumulated according to the team member role: developer, tester, analyst or project manager.

The organization has the specific roles defined: Project manager, Technical Manager, Quality Manager, Configuration Manager, Test Manager, Technical Members. It is possible to accommodate the several roles specified within the organization $\rightarrow$ Impact Classification: Small Benefit [3].

Planning - Launch - The TSP defines a Launch process that includes a well defined set of activities, typically divided into four days: Day 1: 1. Establish Product and Business Goals, Day 1: 2. Assign Roles and Define Team Goals, Day 1: 3. Produce Development Strategy, Day 2: 4. Build Top-down and Next-Phase Plans, Day 2: 5. Develop the Quality Plan, Day 2: 6. Build Bottom-up and Consolidated Plans, Day 3: 7. Conduct Risk Assessment, Day 3: 8. Prepare Management Briefing and Launch Report, Day 4: 9. Hold Management Review and Day 4: Launch Postmortem. The most important aspect of this launch process is the fact that all the team is fully involved in the process, building a real commitment to the project.

At the organization the planning activities that proceed the kick off meeting are related with the specified above, but the work is essentially done by the project manager with the validation of some members of the team. This is an important shift on the way the project is planned $\rightarrow$ Impact Classification: Large Benefit [1].

Monitoring - Project Meetings - The TSP advocates a weekly project meeting based on a specific script.

At the organization meetings occur with the whole team. It is necessary to validate the institutionalization of the process within the whole organization $\rightarrow$ Impact Classification: Small Benefit [3].

Monitoring - Project Reporting - TSP provides a complete set of tools for quantitative project management including: planned value, earned value, predicted earned value, estimation accuracy for size, time, quality, productivity and estimation parameters.

At the present moment the organization has the project reporting based on the information provided by the Microsoft Excel with a very small set of information $\rightarrow$ Impact Classification: Large Benefit [1].

[The organization on-going work] New tools will be deployed during the next 6 months across the whole organization.

Closing - Post Mortem - The TSP defines a process for the post mortem analysis based on quantitative data. This process is critical for the development of the team maturity after each phase and each project.

The organization has a defined process for the post-mortem analysis - Lessons Learnt. However it does not always happen and information is not spread through the organization $\rightarrow$ Impact Classification: Large Benefit [1]. 
TSP gap analysis methodology

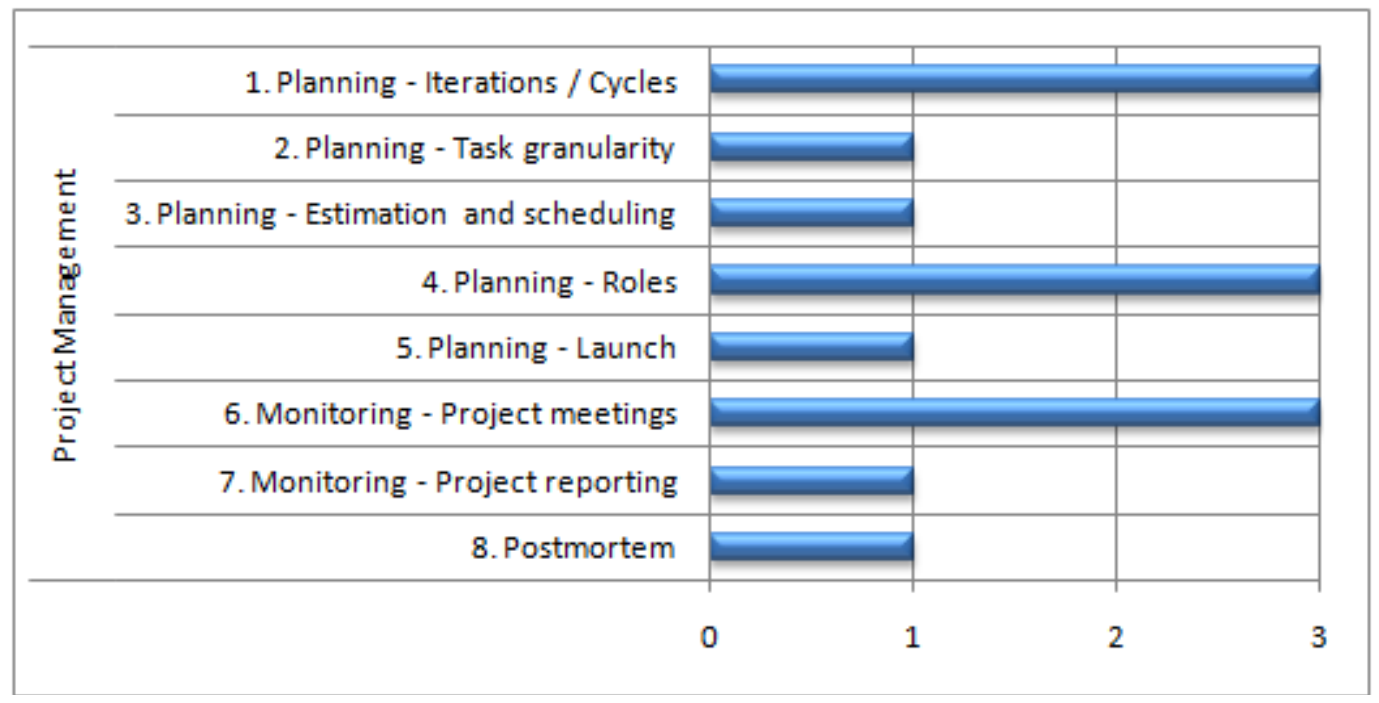

Figure 3.6 - Project Management Evaluation

\subsubsection{Engineering}

The engineering perspective is divided in six topics: Overall Software Development Process (SDP), Requirements, High-Level Design, Detailed Design, Coding and Integration. Verification and validation activities are considered on a separate topic as they are one of main characteristics that differentiate TSP from industry processes.

Overall Software Development Process - TSP has built in the typical phases for the software development: requirements (requirements specification, system testing plan), design (high-level design, integration testing plan), implementation (detailed design, coding, unit testing), integration and testing (build, integration tests, system test). It does not mandate a particular SDP. In the project launch the team selects the SDP.

The organization allows tailoring of the process according to the nature of the project (e.g. prototyping, new development and high reuse). According to the tailoring process, different emphasis can be applied to each process phase $\rightarrow$ Impact Classification: Small Benefit [3].

Requirements - TSP defines a series of specified deliverables regarding requirements management and definition (software requirements specification, uses cases, prototypes, etc.). There are scripts and procedures for requirements management (requirements changes and replanning).

The organization has a well defined requirements process which also includes specific deliverables and processes $\rightarrow$ Impact Classification: Small Benefit [3].

High-Level Design - TSP defines that the desired system should be decomposed into modules that can be implemented by individual engineers. Traceability of parts (sub-systems, components, classes, etc.) to system functions.

In the organization, the software architectural design is produced in the requirements engineering phase. The produced design can have a very detailed level. It is established the traceability of components to requirements through specific tools $\rightarrow$ Impact Classification: Small Benefit [3].

Detailed Design - TSP advocates that the detailed design must be produced before coding - allowing detailed design reviews before coding. Several templates are provided for design 
specification: operational (scenarios), functional (classes), state (state machines), and logic (algorithms) specification templates. Data shows that doing the detailed design before coding significantly reduces the amount of time of correction or reworking.

The organization has a slightly different approach: it emphasizes the assurance of consistency between detailed design and code, by extracting the detailed design from code, according to the sequence think-code-document. Detailed design specifications are usually produced after coding, (when they are produced). Although the QMS clearly states on the construction process that the developer must think before coding this is not the same as developing a detailed design. It is clear that not all the projects produce a detailed design before coding $\rightarrow$ Impact Classification: Medium Benefit [2].

Coding - TSP recommends the use of best standards and guidelines for coding.

The organization also the uses of best standards and guidelines for coding $\rightarrow$ Impact Classification: Small Benefit [3].

Integration - TSP recommends the integration of high quality components. Several integration strategies are recommended.

The organization applied continuous integration on all its projects $\rightarrow$ Impact Classification: Small Benefit [3].

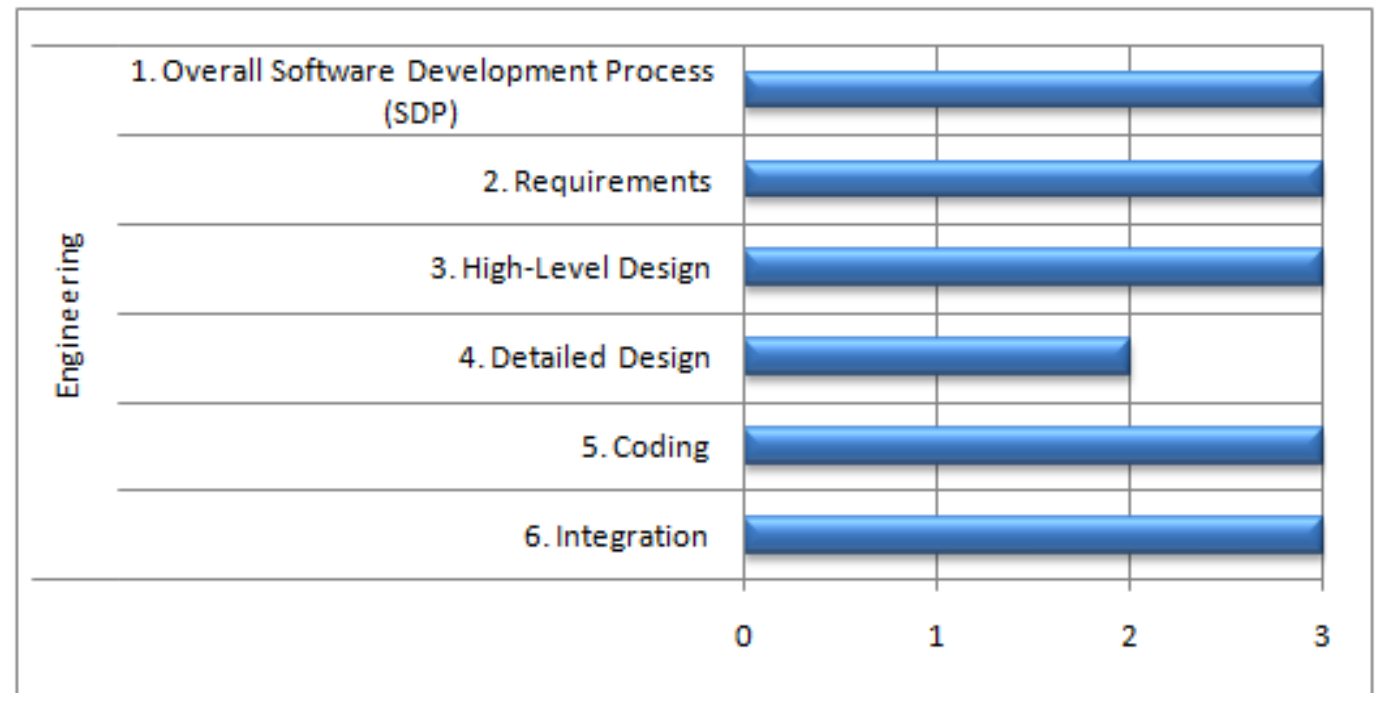

Figure 3.7 - Engineering Evaluation

\subsubsection{Verification \& Validation}

The verification and validation perspective was divided into six topics: personal reviews, team inspections, unit testing, integration testing, system testing and acceptance testing.

Personal reviews - TSP requires that each phase and artifact go through a personal review following a formal procedure (review script), specific standards (design/code/etc.) and a personal checklist. Review activities and defects are registered and personal checklists are continuously improved based on past personal defect data.

At the organization no formal personal review is performed at any phase of the development process $\rightarrow$ Impact Classification: Large Benefit [1]. 
Team inspections - TSP requires that all artifacts are inspected, including unit tests scripts and detailed designs. The inspections must follow an inspection script, specific checklists and standards (e.g. rode and design standards). Checklists are continuously improved based on past defect data. Plans for preparation time and number of reviewers are based on quality criteria (e.g. review rates, yields, etc.), artifact size and development time. Results are reported in a standard form, identifying the inspectors that discovered each defect to allow the estimation of the total number of defects. All defects found are recorded in the defect database.

In the organization no inspections take place and there is no process constructed for this purpose $\rightarrow$ Impact Classification: Large Benefit [1].

Unit Testing - In TSP unit tests are planned and developed after detailed design, and inspected together with this design before coding. Test activities and defects are registered. If a high number of defects are detected, the code may have to be re-inspected, because defects detected in this phase are good predictors of defects in integration and system testing.

In the organization automated unit tests are usually developed after coding. Test activities and defects are not registered $\rightarrow$ Impact Classification: Medium Benefit [2].

Integration Testing - TSP defines that integration test plans are produced and reviewed after the high-level design, and are inspected together with it. Integration tests are executed after each build, before system tests. Test activities and defects are recorded.

In the organization integration test plans are produced after high-level design. Integration tests are often performed together with system testing, except when modules are developed by different partners $\rightarrow$ Impact Classification: Small Benefit [3].

System Testing - In TSP the system test plan is produced and reviewed after the requirements, and is inspected together with the requirements specification. System test procedures and facilities are developed and reviewed during the plan inspection period. System tests are executed after build and integration testing. System test activities and defects are registered.

In the organization the system test plan is produced after requirements. Systems test cases should be specified in a tool with traceability to requirements. Defects found in system testing are registered $\rightarrow$ Impact Classification: Small Benefit [3].

[The organization on-going work] Some projects have data on the time spent in test activities (development, execution, bug reporting). In some cases it is measured the number of tests executed and succeeded along time.

Acceptance Testing - TSP is not prescriptive about this subject.

The organization defines that a customer representative should participate in acceptance testing and this phase is well planned at the beginning of the project $\rightarrow$ Impact Classification: Small Benefit [3]. 
TSP gap analysis methodology

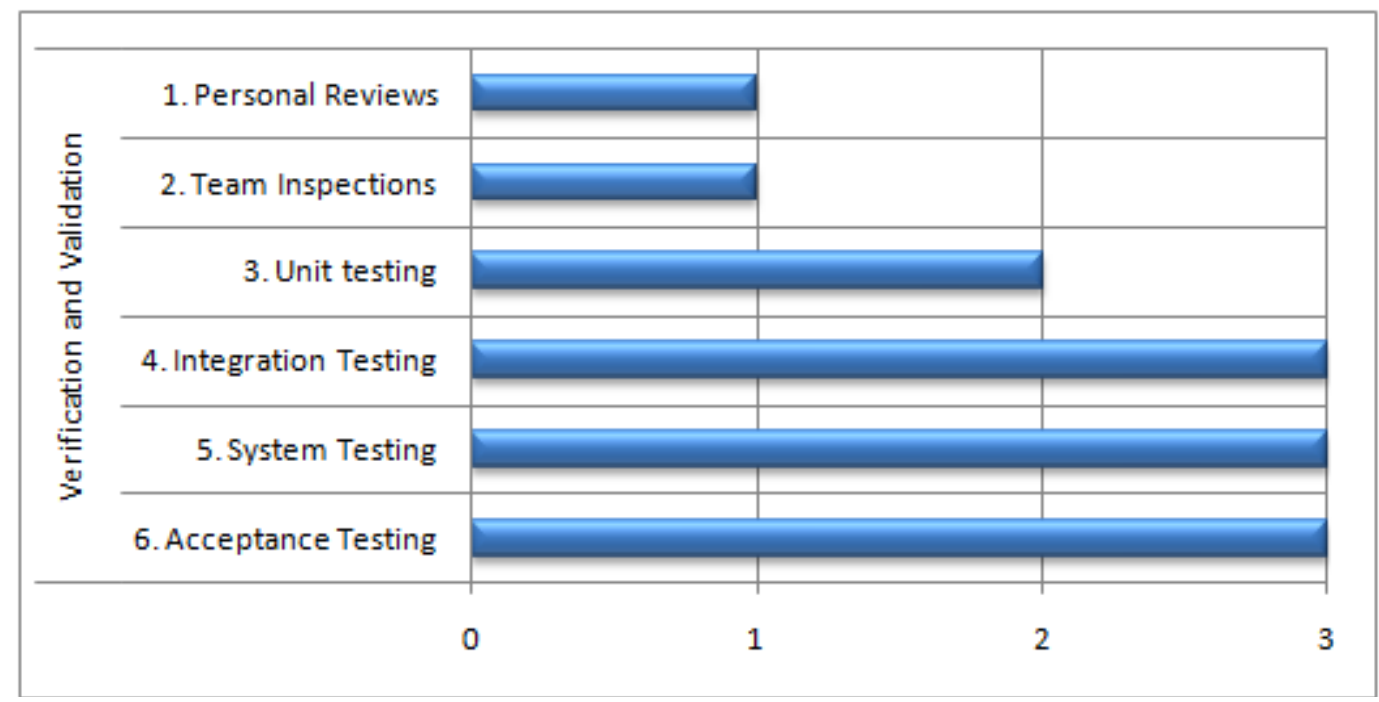

Figure 3.8 - Verification and validation Evaluation

\subsubsection{Process Management}

The process management perspective is divided into four topics: process tailoring, process improvement, process definition and process assurance.

Process Tailoring - TSP permits process tailoring on a specific step defined in the launch process, led by the Process Manager role. Project cycles may have an adaptable scope (e.g. Requirements or High-level Design).

In the organization tailored guidelines are specified in many parts and points of the processes. Lifecycles are suggested according to the project context: Prototype, New Development and High Reuse $\rightarrow$ Impact Classification: Small Benefit [3]

Process Improvement - TSP emphasizes that the process improvement is based on data and not not in opinions. There are specific process improvement proposals (PIP) forms filled by each member of the team on each post-mortem.

At the organization suggestions are submitted by individuals through a specific tool and received by the QMS department. Improvement suggestions are validated with the process owner to validate and plan changes $\rightarrow$ Impact Classification: Medium Benefit [2].

Process Definition - TSP focuses on the software development and related processes (configuration management, requirements development, testing, design, implementation, launch, postmortem, etc.). Process definitions are based on scripts, forms and standards. Each script has entry criteria, general description, detailed steps and exit criteria.

The QMS of the organization is very poor, although a lot of processes are institutionalized in the organization $\rightarrow$ Impact Classification: Large Benefit [1].

Process Assurance - In the TSP the process assurance is implemented by the team member who has the process manager role.

In the organization this function is now assigned to the Quality Manager who assures that the process adherence follows the QMS $\rightarrow$ Impact Classification: Small Benefit [3]. 
TSP gap analysis methodology

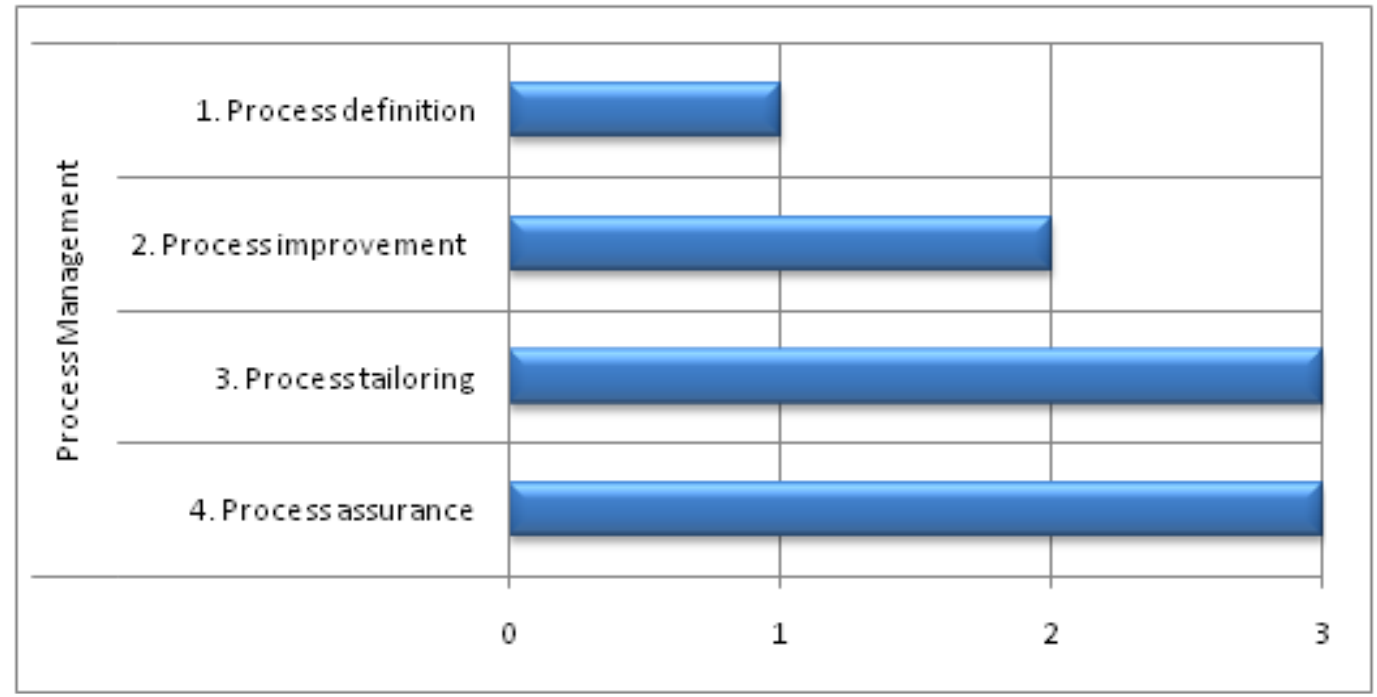

Figure 3.9 - Process Management Evaluation

\subsubsection{Performance Analysis (RTE section 7)}

For the purpose of making an analysis of the current organization's performance regarding its software development performance, the organization was asked for measurement information regarding some projects. At present time the organization is starting to quantitatively manage some projects and due to this activity being in its early phases there is not much information available.

\subsubsection{Data received}

The selected project for analysis had the following information available:

- Type: Application, Technology: Java and C\#

- Resources: 17 different people, with different roles and degrees of participation equivalent to an average of 4.5 full time equivalent (FTE) stable over time

- $\quad$ Size (lines of code) - Total Produced: 46459 (There was reuse but it is not quantified)

- Total Effort (hours) - Planned: 6300; Real: 8698.92

- Effort Per phase (hours)

- Requirements: 812;

- Development: 841;

- System testing: 2497;

- Acceptance Testing: 145;

- Project Management, Configuration Management, Test Cases development: 1048

- Schedule (weeks) - Planned: 35; Real: 66.5

- Defects - Unit testing: 340; System testing: 1005 
TSP gap analysis methodology

\subsubsection{Analysis and Benchmarking}

With the available data some derived measures were calculated and a project simulation was made with the size of the project and the typical benchmarks for TSP.

Simulation assumptions:

1. TSP productivity 7.5 LOC (lines of code) per Hour of productivity

2. All construction was new developed code

3. Productivity is calculated by the division between lines of code produced and effort of the project.

\begin{tabular}{|c|c|c|c|c|}
\hline \multirow[b]{3}{*}{ Ettort (Hours) } & \multicolumn{2}{|c|}{ Orgenizstion } & \multicolumn{2}{|c|}{ TP } \\
\hline & Planned & Res: & $\begin{array}{l}\text { Simulationtor } \\
\text { this Project }\end{array}$ & Benchmerk \\
\hline & 6300 & $8598.92(+3896)$ & 6195 & < $9 \%$ varience \\
\hline Schedule(Weeis) & 35 & $65.9(+9096)$ & 48 & < $10 \%$ variande \\
\hline Defexts Unit teting & - & 340 & 33,8 & - \\
\hline Defects S/atem Testing & - & 1005 & 4,3 & - \\
\hline Defext Density U nit Testing (Defest/KLOC) & - & 7,32 & 0,84 & - \\
\hline Defert Density System Tes fing (Defert/KLOC) & - & 21,63 & 0,08 & $0-0,9$ \\
\hline Productivity (LOC/Hour) & - & 9,3 & 72 & $9-10$ \\
\hline
\end{tabular}

Table 3.5 - Analysis and benchmarking

Some considerations to have into account when analyzing the results:

- This type of data seems to be a perspective from a real project and with a performance in line with the industry benchmark for an organization with this maturity.

- The major benefits that TSP can bring will be a strong improvement in effort and schedule predictability as well as product quality and cost of quality.

- The amount of defects found on system testing show that quality activities are being performed at very late stages of the development process. In this project, the product was probably shipped with a lot of defects. The cost of quality is too high.

- The levels of productivity can have a good degree of improvement. This increase will boost the level of profitability, especially on large projects.

- The analysis assumed that there was no reuse in the project which can lead to even better TSP results for schedule and productivity.

- These numbers refer to only one project data. 


\section{Practical implementation}

After the work done at organization together with the meetings that have been held regarding the implementation of TSP, several gaps were identified.

These gaps cover mostly the areas of measurement, quality management, self-directed team, coaching, training and performance.

In order to overcome these gaps for the implementation of TSP there were several measures that have been recommended:

1. Plan the implementation of TSP in 2 pilot projects that are considered business relevant and representative of the work of the organization.

2. Pick projects that have a planned duration between 3 and 6 months.

3. Assign resources that are either willing to embrace this new challenge or are seen as early adopters inside of the organization (the teams should be between 5 and 15 people).

4. Plan the TSP and PSP training to be delivered as soon as possible.

5. Adopt the SEI tools for the pilots.

6. After the pilot project has started, conduct a gap analysis of the tools in order to plan and implement the SEI tools requirements in the organization's tools.

By using TSP methodologies, organizations can achieve a quick start to process improvement, and can accelerate and better sustain process improvement initiatives already underway. The TSP framework is a proven-effective way for organizations to implement a successful process improvement effort.

It is important to restate that no further information can be provided due to confidentiality agreements. 


\section{Conclusions and future work}

\subsection{Fulfillment of objectives}

This dissertation presents a methodology for assessing an organization on TSP practices. Throughout this dissertation several decisions and actions have been taken in order to develop the methodology. The author concludes that the objectives of this dissertation have been fully accomplished. This fact becomes more evident after the application of the methodology and the praise received both by the management of the organization that was assessed as well as by the Software Engineering Institute that reviewed this assessment.

Prior to starting developing this methodology it were deeply studied other already existing assessment methods. Having into account the complexity of these other methodologies and the cost involved in executing them, the author tried to produce a simple methodology that would produce accurate results for evaluating the needs and gains of implementing TSP in an organization.

It has been given special attention to the interviews that have to be conducted during the application of this methodology. The order of the questions and of the sections, open and closed questions has been set so that the interviewed can gain confidence on the assessment team as well as information beyond the questions can be gathered. There has also been the concern on the time taken for each interview in order to make it cost effective and enthusiastic.

After the development of the questionnaires, and before its use on a real case, they have been reviewed by senior software engineers with TSP knowledge in order to validate its content. The comments received were very positive.

The report template has been developed with the objective of facilitating the development and delivery of the final report to the organization management. It has the advantage of being simple, easy to read and having in its structure an interpretation of the assessment areas. 


\subsection{Future work}

Future research in this field can improve the methodology described as well as improve the tools available for the assessment team. At this stage there is no tool to support the gathering of information. A tool for helping the assessment could be of great help for the team as it could speed up the developing of the report as well as gathering structured information.

Furthermore, the author believes that applying this methodology to different types of organization in terms of size, level of maturity or site-spread organizations can bring extra input to develop the methodology and even create different approaches according to this type of organization. 


\section{References}

[IEEE1990] IEEE. IEEE Standard Glossary of Software Engineering Terminology. , , 1990.

[GARCIA2008] Ivette Garcia. PROSOFT - TSP National Initiative, 2008. .

[HUMP2006a] Watts S. Humphrey. TSP Leading a Development Team. AddisonWesley, , 2006.

[HUMP2002] Watts S. Humphrey. Winning with software. Addison-Wesley, 1st, 2002.

[HUMP1997] Watts S. Humphrey. Introduction to the Personal Software Process. Addison-Wesley, , 1997.

[OVER2008] Jim Over. Team Software Process is CMMI!. In , pp. . SEI, 2008.

[HUMP2006b] Watts S. Humphrey. TSP Coaching Development Teams. Addison-Wesley, , 2006.

[DAVIS2003] Noopur Davis, Julia Mullaney. The Team SoftwareProcess (TSP) in Practice: A Summaryof Recent Results. , 2003.

[SMITH2008] Jeffrey Smith, Radhika G Janardanan. Delivering Successful Projects with TSP, 2008.

[ARMAND2006] David Saint-Armand. Process Improvement at NAVAIR using TSP and CMM. In , pp. ., 2006.

[HUMP2008] Watts S. Humphrey, Bill Nichols. Certifying Software Organizations. In , pp. ., 2008.

[CRISIS2007] Mary Beth Crisis, Mike Konrad, Sandy Shrum. CMMI for Development. Addison-Wesley, , 2007.

[SEI2009b] SEI. SEI CMMI FAQ, 2009. http://www.sei.cmu.edu/cmmi/faq/his-faq.html .

[ISOIEC2004a] .ISO/IEC 15504-2 Software Engineering - Process Assessment - Part 2 - Performing an Assessment. , , 2004.

[ISO2009] . Wikipedia: ISO 15504, 2009. http://en.wikipedia.org/wiki/ISO_15504 .

[ARC2006] SCAMPI Upgrade Team. AppraisalRequirements forCMMI®, Version 1.2. SEI, , 2006.

[AHERN20005] Dennis M. Ahern, Jim Armstrong, Aaron Closure, Jack R. Ferguson, Will Hayes, Kenneth E. Nidiffer. CMMI SCAMPI Distilled appraisals for Process Improvement. Addison-Wesley, , 2005.

[SCAMPI2006] SCAMPI Upgrade Team. Standard CMMI Appraisal Method for Process Improvement (SCAMPI) A, Version 1.2: Method Definition Document. SEI, , 2006. 
Conclusions and future work

[ISOIEC2004b] . ISO/IEC 15504-2 Software Engineering - Process Assessment - Part 3 - Guidance on Performing an Assessment. , , 2004.

[CAPPRO2009] . Appraisal Assistant Capability Profile, 2009. http://www.sqi.gu.edu.au/AppraisalAssistant/ss/i15504result.jpg .

[SEI2009a] SEI. Software Engineering Institute, 2009. http://www.sei.cmu.edu .

[IBM2002] IIBM. ODC, 2002. http://www.research.ibm.com/softeng/ODC/ODC.HTM . 